University of Louisville

ThinkIR: The University of Louisville's Institutional Repository

$4-2009$

\title{
Investigation of wheelchair ingress/egress activities in large accessible transit vehicles and evaluation of ADA ramp guidelines for improved ramp safety and usability.
}

Sheryll Sison

University of Louisville

Follow this and additional works at: https://ir.library.louisville.edu/etd

\section{Recommended Citation}

Sison, Sheryll, "Investigation of wheelchair ingress/egress activities in large accessible transit vehicles and evaluation of ADA ramp guidelines for improved ramp safety and usability." (2009). Electronic Theses and Dissertations. Paper 1334.

https://doi.org/10.18297/etd/1334

This Master's Thesis is brought to you for free and open access by ThinkIR: The University of Louisville's Institutional Repository. It has been accepted for inclusion in Electronic Theses and Dissertations by an authorized administrator of ThinkIR: The University of Louisville's Institutional Repository. This title appears here courtesy of the author, who has retained all other copyrights. For more information, please contact thinkir@louisville.edu. 
INVESTIGATION OF WHEELCHAIR INGRESS/EGRESS ACTIVITIES IN LARGE ACCESSIBLE TRANSIT VEHICLES AND EVALUATION OF ADA RAMP GUIDELINES FOR IMPROVED RAMP SAFETY AND USABILITY

\title{
By
}

Sheryll Sison

B.S., University of Louisville, 2007

\author{
A Thesis \\ Submitted to the Faculty of the \\ University of Louisville \\ J.B. Speed School of Engineering \\ in Partial Fulfillment of the Requirements \\ for the Professional Degree
}

MASTERS OF ENGINEERING

Department of Mechanical Engineering

April 2009 
INVESTIGATION OF WHEELCHAIR INGRESS/EGRESS ACTIVITIES IN LARGE ACCESSIBLE TRANSIT VEHICLES AND EVALUATION OF ADA RAMP GUIDELINES FOR IMPROVED RAMP SAFETY AND USABILITY

Submitted by:

Sheryll Sison, B.S.

A Thesis Approved On

(Date)

by the Following Reading and Examination Committee:

Gina E. Bertocci, PhD, PE, Co-Thesis Director

Karen L. Frost, PhD, MBA, Co-Thesis Director

Mary Ellen Buning, PhD, OTR/L, ATP

Naira Campbell-Kyureghyan, $\mathrm{PhD}$

Peter Quesada, PhD 


\section{ACKNOWLEDGEMENTS}

This study was funded by the National Institute on Disability and Rehabilitation Research (NIDRR) and the Rehabilitation Engineering Research Center (RERC) on Wheelchair Transportation, Grant \#H133E060064. The author would like to thank the Transit Authority of River City (TARC), especially Russ Rakestraw, Mike Todovich, Judy Howard, and Barry Barker for providing access to this valuable data. The author would also like to thank the member of the thesis committee, Dr. Gina Bertocci, Dr. Karen Frost, Dr. Mary Ellen Buning, Dr. Naira Campbell-Kyureghyan, and Dr. Peter Quesada. 


\begin{abstract}
There is limited information regarding usability and safety during wheelchairseated passenger ingress/egress activities in large accessible transit vehicles (LATVs). The purpose of this study was to review and characterize wheelchair ingress and egress activities occurring on LATVs and examine factors that may contribute to adverse events. Through a review of wheelchair boarding and alighting video events, 108 ingress and 108 egress events were captured and documented in a database form with limited predetermined response options. In this study, 26 of $216(12 \%)$ total ingress/egress events resulted in passenger difficulty or an incident. Factors appearing to contribute to adverse ingress events involved the use of a rear-facing orientation $(64 \%, n=14)$. Factors relating to ramp slope, which is influenced by ramp extension level, appeared to contribute to adverse events, primarily during ingress due to increased angle of incline of the ramp. Human factors directly related to the wheelchair-seated passenger contributed to 17 $(77 \%)$ adverse ingress events and all egress $(n=4)$ events. Through an evaluation of adverse events with respect to ADA guidelines, ramp width and ramp threshold appeared to play a role in passenger difficulties and incidents. Design and training recommendations were made to improve safety, accessibility, and usability of future ramp designs to help transit providers enhance LATV operator procedures.
\end{abstract}




\section{TABLE OF CONTENTS}

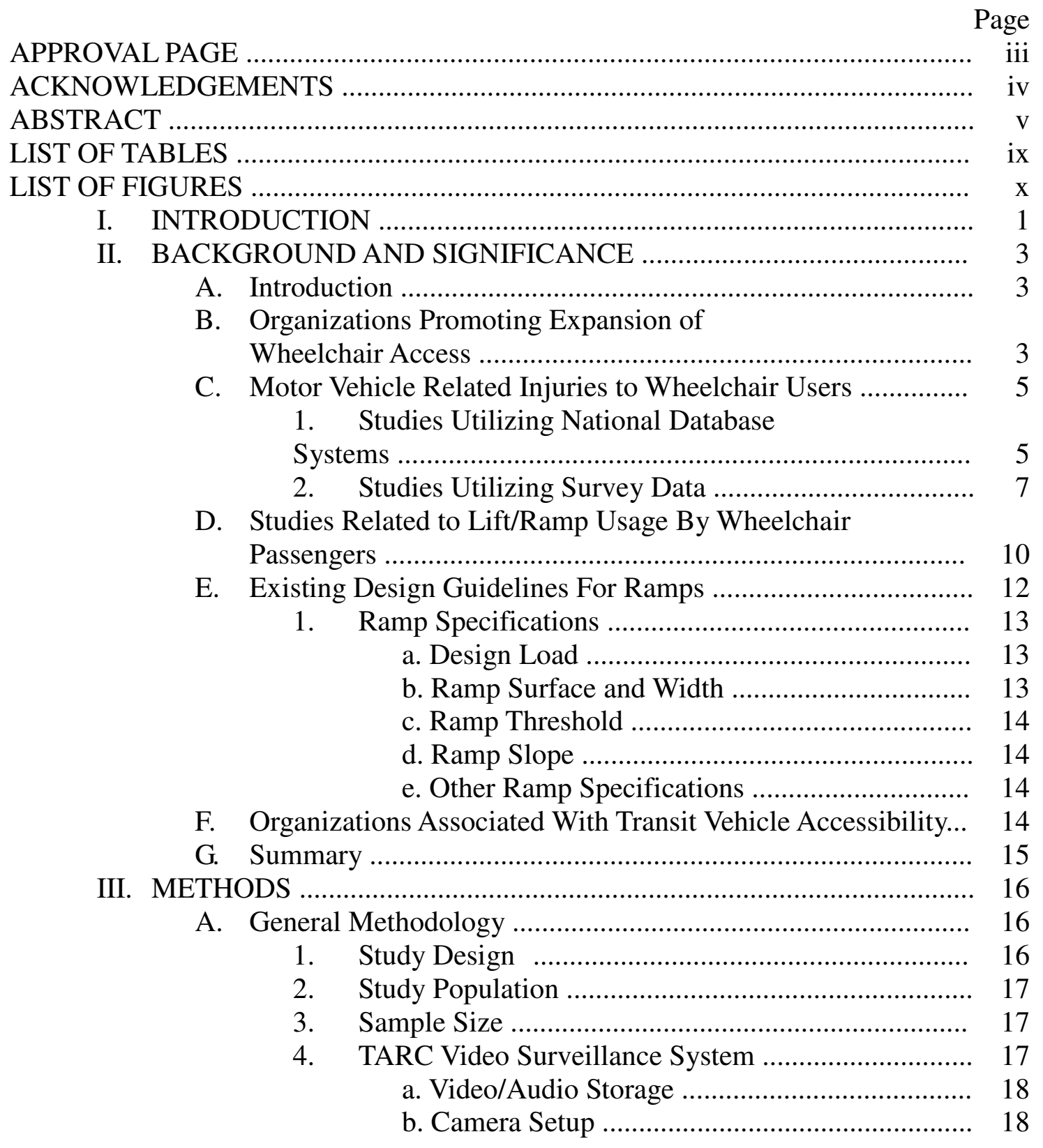


B. Specific Aim 1: Review of Public Transit Video $\quad$ Page

1. Obtaining Video Surveillance Footage ..................... 19

2. Wheelchair Ingress/Egress Event Video Capture .......................................................... 19

C. Specific Aim 2: Characterizing Adverse Ingress/Egress Events .......................................................... 20

1. Ingress/Egress Variables ......................................... 20

2. Video Database/ Data Recording ............................... 23

3. Video Data Analysis ................................................. 24

D. Specific Aim 3: Evaluating Ramp Adequacy ………………..... 24

1. Adverse Event Variables .......................................... 24

2. Adverse Event Video Data Analysis ......................... 26

IV. RESULTS

A. Specific Aim 1: Wheelchair Ingress/Egress

Characteristics .................................................................. 27

1. General Information ............................................ 27

2. Ingress and Egress Activities .................................... 28

a. Ingress Activities ………………………...... 28

b. Egress Activities ............................................. 29

B. Specific Aim 2: Characterizing Adverse Events ....................... 31

1. Frequency of Adverse Events ................................... 31

2. Adverse Events By Wheelchair Type …………….... 32

3. Adverse Events By Ramp Extension Level .............. 33

4. Adverse Events By Wheelchair Orientation .............. 35

5. Adverse Events By Passenger Assistance ................. 36

C. Specific Aim 3: Evaluating ADA Guidelines ……………........ 37

1. Adverse Ingress Events ........................................... 37

2. Adverse Egress Events .............................................. 38

V. DISCUSSION ........................................................................ 40

A. General Ingress/Egress Activities .......................................... 40

1. Wheelchair Orientation ............................................. 40

2. Ramp Extension Level ............................................. 41

3. Assistance .............................................................. 43

B. Adverse Ingress/Egress Events ................................................ 44

1. $\quad$ Ramp Width ......................................................... 44

2. $\quad$ Ramp Slope and Ramp Extension ........................... 45

3. Ramp Side Barriers .................................................. 46

4. Ramp Threshold .................................................... 47

5. LATV Components ................................................. 48

6. Human Factors: Wheelchair-Seated Passenger ......... 50 
7. Page

7. Operator Factor ................................................... 51

C. Perception of Time in Fixed-Route Schedules....................... 53

D. Limitations ................................................................... 55

E. Recommendations for Future Ramp Safety

Guidelines ................................................................... 56

1. Design Opportunities ...................................... 56

2. Training Opportunities .......................................... 57

VI. CONCLUSIONS ...................................................................... 59

REFERENCES ................................................................................... 60

APPENDIX I. WHEELCHAIR TRANSPORTATION MONITORING

DATABASE (INGRESS/EGRESS) .................................................................... 62

APPENDIX II. ADVERSE INGRESS EVENT EVALUATION OF CURRENT

LEGISLATIVE GUIDELINES ...................................................................... 64

APPENDIX III. ADVERSE EGRESS EVENT EVALUATION OF CURRENT

LEGISLATIVE GUIDELINES ..................................................................... 76

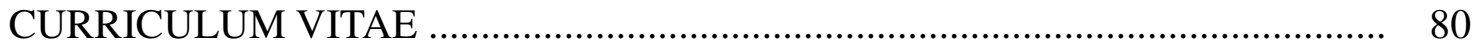




\section{LIST OF TABLES}

Page

Table I: Ingress/Egress Variable Definitions

21

Table II: Adverse Event Variable Definitions

Table III: Wheelchair Type, Passenger Gender, and Driving Conditions for

Wheelchair Ingress/Egress Events....

28

Table IV: Wheelchair Ingress and Egress Characteristics ................................. 30

Table V: Frequencies of Passenger Difficulties or Incidents .............................. 32

Table VI: Adequacy of Ramp Related Design Variables During Adverse

Ingress Events Based on Current ADA Specifications

Table VII: Adequacy of Ramp Related Design Variables During Adverse

Egress Events Based on Current ADA Specifications............................................ 39

Table VIII: Measured TARC LATV Ramp Angles ................................................. 43

Table IX: Leading Conditions Associated with Mobility Device Use.................... 51

Table X: Completion Times of Ingress and Egress Events ................................... 54 


\section{LIST OF FIGURES}

$\begin{array}{ll} & \text { Page }\end{array}$

Figure 1. TARC LATV 4-Camera Setup ...................................................... 19

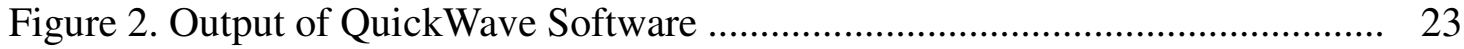

Figure 3. Adverse Events: Wheelchair Type .................................................... 33

Figure 4. Adverse Events: Ramp Extension ..................................................... 34

Figure 5. Adverse Events: Wheelchair Orientation ........................................... 35

Figure 6. Adverse Events: Assistance Required or Provided ............................... 36

Figure 7. Ramp Angle Associated With Ingress/Egress Events ........................... 42

Figure 8. TARC LATV Ramp Side Barriers ......................................................... 47

Figure 9. TARC LATV Ramp Threshold .......................................................... 48

Figure 10. Interior TARC LATV Components in Access Path ............................... 49

Figure 11. Example of Ramp Deployment onto Uneven Surfaces ......................... 52 


\section{Introduction}

The 1990 Americans with Disabilities Act mandates that persons with disabilities be provided access to public transportation (ADA, 1990). Based on the 2002 U.S. Census Bureau Report, there are an estimated 2.7 million persons over 15 years of age who use wheelchairs and/or scooters (US Census, 2002). Many of these wheelchair users rely on large accessible transit vehicles (LATVs) to get to work, school, medical appointments or other activities.

The National Highway Traffic Safety Administration estimated that between 1991 and $1995,25 \%$ of 7,121 motor vehicle-related injuries or deaths to wheelchair users were a result of either lift malfunction or falling on/off the ramp (NHTSA, 1997). In a recent 4year retrospective study of wheelchair users on LATVs, $59 \%$ of operator-reported incidents occurred during ingress or egress when the wheelchair user was on the ramp; $14 \%$ of which resulted in an injury (Frost and Bertocci, 2006).

Given the current state of incidents/injuries related to wheelchair users and wheelchair population increase, there is a need to address wheelchair transportation safety issues. Limited information exists describing incidents or difficulties associated with ingress/egress on LATVs, or factors influencing injury risk when wheelchair riders board and exit the LATV. In this study, wheelchair ingress/egress activities on LATVs were reviewed by wheelchair type, ramp extension level, wheelchair orientation on ramp, and exterior surface terrain in order to assess factors that influence wheelchair user 
difficulty or incidents. Video footage and existing ramp literature (manufacturer, legislative, and voluntary standards) were examined for factors contributing to adverse events. These adverse events were further analyzed to evaluate the adequacy of ADA ramp guidelines for improved ramp safety and usability.

The specific aims for this study are as follows:

1. Review public transit video surveillance footage of wheelchair ingress/egress events to gain an understanding of activity patterns relating to ingress/egress and characterize factor leading to adverse events.

2. Characterize adverse wheelchair-related ingress/egress events by type of event, wheelchair type, environmental conditions, and outer terrain surface types.

3. Evaluate the adequacy of current legislative guidelines (Americans with Disabilities Act and the Federal Transit Administration) as they relate to wheelchair ramp design. 


\section{Background and Significance}

\section{$\underline{\text { A. Introduction }}$}

The 1990 Americans with Disabilities Act mandates that persons with disabilities be provided access to public transportation to ensure full participation in society. This legislation requires public transit agencies to provide wheelchair users with access to vehicles via lifts and ramps (ADA, 1990). Based on the 2002 U.S. Census Bureau Report, there are an estimated 2.7 million persons over 15 years of age who use wheelchairs and/or scooters (U.S. Census, 2002) as their primary means of mobility. Many of these wheelchair users require public transit to travel to work, school, medical appointments, and other activities.

\section{B. Organizations Promoting Expansion of Wheelchair Access}

There has been continual growth in the number of wheelchair users due to technological and social factors such as the increase in access to mobility technology and the demand to expand wheelchair access in the community (LaPlante, 2003). In addition, individuals with family incomes less than $\$ 10,000$ are 6 times more likely to be mobility device users (including walking device users and wheelchair users) and 4.6 times more 
likely to be a wheelchair user compared to individuals with family incomes of $\$ 35,000$ or greater (Kaye, 2000). The high variation in device user rates is likely due to the increase of retirement persons associated with lower incomes. Since mobility device use is greater for persons with lower incomes, it is likely that this subset of the wheelchair population will use public transportation as their primary means of transportation.

Several organizations are dedicated to addressing the needs for persons with disabilities. The National Council on Disability (NCD), for example, is a group appointed by the U.S. President and provides advice to Congress and executive agencies to promote programs and policies relating to equal opportunity for persons with disabilities (www.ncd.gov). One of their main recommendations in regards to public transit vehicles is for the establishment of accessibility equipment maintenance programs. This involves requiring transit agencies to implement regulatory maintenance checks for accessibility equipment and establish protocols to discharge LATVs with malfunctioning lifts/ramps from service (NCD, 2005).

Another organization advocating for transportation for persons with disabilities is Project ACTION, a funded collaborative of Easter Seals and the U.S. Department of Transportation. This collaborative was established to promote cooperation between transit agencies and disability communities and to provide resources such as operator training (projectaction.easterseals.com). Also contributing to the expansion in wheelchair access is the New Freedom Initiative of 2001. The goals of this initiative are to increase access to assistive technologies, expand educational opportunities, integrate persons with disabilities into the workforce, and promote full access to community life (Bush, 2001). Overall, each of these organizations advocates for ADA requirements and the evolving 
needs of the wheelchair user population to bridge the gap between transit agencies and the disability population.

With the increase of wheelchair users, wheelchair access, and demand for public transportation, it is necessary to ensure that transportation safety is adequately addressed. In a 5-year study, the National Highway and Traffic Safety Administration (NHTSA) estimated 7,121 wheelchair riders were injured or killed in motor vehicle-related incidents, with lift malfunction and falling on/off the access ramp constituting $25 \%$ of the injuries or deaths (NHTSA, 1997). To gain a better understanding of factors that may contribute to these injuries, not only must events occurring during transit (when the vehicle is moving) be considered, but also events during ingress and egress, where wheelchair passengers have reported a greater frequency of injuries (Fitzgerald, 2007).

\section{Motor Vehicle Related Injuries to Wheelchair Users}

\section{$\underline{\text { 1. Studies Utilizing National Database Systems }}$}

Little is known about the injury risk related to wheelchair users while riding in motor vehicles. To quantify risk associated with wheelchair users in motor vehicles, Richardson (1991) and Shaw (2000) examined the National Electronic Injury Surveillance System (NEISS) database (Richardson, 1991 and Shaw, 2000). Data collected in the NEISS database is gathered from 95 of approximately 6,000 hospitals nationwide. Data is accrued from reported emergency visits involving an injury associated with a wheelchair user (www.cpsc.gov). Richardson estimated that 2,200 
wheelchair-related injuries occurred in motor vehicles from 1986 to 1990 (Richardson, 1991). Shaw identified 33 wheelchair injury events associated with improper seating securement and restrain systems while using motor vehicles between January 1988 and September 1996, from which he estimated 1,320 wheelchair injuries nationwide (Shaw, 2000). This discrepancy in the estimated wheelchair injury events across studies indicates the limitations of using NEISS data to define wheelchair injury risk. While Richardson searched for general wheelchair injuries in motor vehicles, Shaw queried for wheelchair injuries involving wheelchair securement and restraint. However, both Shaw and Richardson concluded that the majority of the incidents occurred during low g situations such as sudden stops and sharp turns.

Shaw (2000) recognized the limitations of the NEISS database, such as lack of sufficient details and inconsistent reporting, classification of vehicle type, and the absence of deaths per passenger mile data, all of which were needed to establish wheelchair injury risk (Shaw, 2000). Therefore, he used an alternate approach to gain a better understanding of wheelchair-related injuries in motor vehicles by using accident fatality data. He reviewed the Fatal Accident Reporting System (FARS) database from 1989 to 1994 for fatalities associated with passengers aboard wheelchair transport vehicles. The FARS database is maintained by NHTSA and consists of a nationwide census of fatal crashes occurring on highways involving a motor vehicle. All data included in the FARS database must have resulted in the death of a person within 30 days of the crash (http://www-nrd.nhtsa.dot.gov). During the study period, Shaw estimated a fatality rate of 0.01 per 100,000 passenger miles occurring on large public vehicles such as school buses and transit buses, which is much lower as compared to small vehicles 
such as minivans ( 0.59 per 100,000 passenger miles) (Shaw, 2000). Fatality rates included all vehicle passengers, both wheelchair and non-wheelchair passengers.

The estimations utilizing the FARS and NEISS data indicate that public transit buses are associated with less risk of death/injury to passengers as compared to small, private vehicles such as vans. Shaw's findings with the NEISS database reported 3 of the 33 reported injuries occurred on public transit buses while the majority (22 injuries) occurred while using a van or a paratransit van (Shaw 2000). There were no wheelchairrelated deaths reported in the NEISS database during the study period. There was also very little information in regard to how the injuries were sustained. Furthermore, only injuries treated in participating hospital emergency rooms were included in the NEISS database (95 of 6,000 hospitals participated in the program). These reports do not include injuries treated in non-emergency facilities, such as urgicare centers and private physician offices. Data from the FARS database is limited because it only covers fatality data due to crashes and does not cover non-crash situations such as emergency maneuvering, sudden braking, and sharp turns.

\section{Studies Utilizing Survey Data}

Other studies recognized the limitations when using the NEISS and FARS databases and took a different approach in investigating injuries to wheelchair passengers while using a motor vehicle. The studies conducted by Songer et al. (2004) and Fitzgerald et al. (2007) used survey data as a means to gain a better understanding of injury frequency experienced by wheelchair users while using a motor vehicle (Songer, 2004 and Fitzgerald, 2007). These researchers surveyed 596 wheelchair users nationwide from 
June 2002 to November 2003. All participants reported using their wheelchair as their primary means of mobility.

Songer et al. (2004) identified the frequency of involvement in a motor vehicle crash and non-crash incident, and the type of motor vehicle associated with the reported incident. He reported $61 \%$ of the 596 survey respondents rode as passengers and used public transportation, which included buses, and paratransit vehicles as their overall means of transportation, averaging 83 miles per week. To quantify the injury frequency, respondents were asked to report any injuries sustained within 3 years of the survey date that resulted in the individual falling out of his/her wheelchair and/or the wheelchair tipping over. Approximately 7\% of the respondents reported being involved in a crash incident. However, more respondents reported being involved in a non-crash incident and sustaining an injury (13.6\%). Non-crash incidents were defined as incidents resulting from quick or sudden braking, sudden or sharp turning, or quick acceleration. Crash situations were highly associated with wheelchair drivers, while non-crash incidents were primarily associated with wheelchair passengers. These findings suggest a greater injury risk for wheelchair users who are passengers in motor vehicles. From this data, Songer et al. calculated an injury rate of 5.2 per 100,000 miles traveled for wheelchair passengers using public vehicles while remaining seated in their wheelchair during transit (Songer, 2004).

Fitzgerald et al. (2007) further examined the survey data based on motor vehicle injury and whether or not the wheelchair user transferred to a vehicle seat or remained seated in his/her wheelchair. Fitzgerald reported that $91 \%$ of wheelchair users who used public vehicles as a passenger remained seated in their wheelchair during transit. Twenty- 
three percent of these wheelchair passengers reported an injury. This percentage was higher than for those who transfer to a vehicle seat (15\%) (Fitzgerald, 2007).

In addition, Fitzgerald et al. also examined barriers to transportation use for wheelchair passengers. Thirty-four percent of the respondents reported barriers in terms of difficulty using transportation service within the past 3 years of the survey date. Difficulty experienced by the respondents included decreased availability/difficulty in scheduling access to public transportation, wheelchair unable to enter motor vehicle, dependence upon others or needing assistance, and poor public transportation driver attitudes. Fifty-six percent of these reported difficulties were from wheelchair users who used public vehicles. Unfortunately, Fitzgerald did not further identify the type of difficulty encountered by these wheelchair users and did not identify the percentage of difficulties that were related to using the lift/ramp. The types of wheelchair associated with the reported difficulties were primarily scooters $(60 \%)$ and power wheelchairs (37.1\%) (Fitzgerald, 2007).

Both Songer and Fitzgerald recognized the limitations associated with their survey studies. First, they did not examine the circumstances surrounding the reported incidents from the respondents. Thus, factors that may have contributed to the reported injury, such as weather conditions and type of assistance required/provided remain unknown. Second, there are limitations regarding the nature of data gathered through surveys. As Songer noted, surveys are typically subject to bias due to under or over reporting of incidents and result in measurement error. Therefore, the respondent and his/her ability to remember or willingness to provide information may influence survey data results (Songer, 2004). 
Despite their limitations, these studies using national databases and surveys give insight to the frequency in which fatalities and injuries occur to wheelchair users in motor vehicles. Shaw reported a fatality rate of 0.01 per 100,000 passenger miles associated with public transit buses from data examined though the FARS database (Shaw, 2000). Songer and Fitzgerald reported a rate of 5.2 injuries per 100,000 passenger miles associated with public vehicle usage (Songer, 2004 and Fitzgerald, 2007). In a comprehensive review of injury and incidents involving wheelchair passengers on motor vehicles, Shaw found that wheelchair users have an accident rate of over 350 times greater than ambulatory passengers and account for 3-10 percent of passenger incidents (Shaw, 2003). The inconsistency in injury estimations implies the need for further investigation regarding the injury risk to wheelchair users while traveling in a motor vehicle. In particular, future work should expand on non-crash situations where injuries most often occur.

\section{Studies Related to Lift/Ramp Usage By Wheelchair Passengers}

There is limited information available about the activities surrounding wheelchair ingress (boarding) and egress (disembarking) associated with motor vehicles. This is important since much of ingress and egress involves the wheelchair passenger's interaction with the vehicle access lift/ramp. In the NHTSA study discussed previously, NHTSA reported that lift malfunction and falling on/off the ramp contributed to $19 \%$ and $6 \%$ of 7,121 injuries/deaths, respectively. There were no deaths reported for these two 
injury producing activities (NHTSA, 1997). Recognizing the limitations of using the NEISS database, Rotko et al. (2005) and Frost and Bertocci (2006) identified the wheelchair passenger injury risk associated with ingress and egress by alternate measures. Rotko et al. utilized a survey method, while Frost and Bertocci reviewed wheelchair related incident reports of a metropolitan transit agency (Rotko, 2005 and Frost, 2006).

Rotko et al. conducted a nationwide survey study to quantify injury risk during ingress and egress in terms of wheelchair type, transportation mode (public or private), and the frequency of an injury. There were 336 respondents who used a wheelchair as their primary means of mobility and remained seated in their wheelchair during transportation. Fifty-three respondents (15.8\%) reported sustaining an injury while using a motor vehicle within 3 years of the survey date. Eighty-six unique injuries were reported. Rotko further identified that $25.8 \%$ of these injuries occurred while using a ramp and 58.4\% of the injuries occurred while using a lift. Approximately $43 \%$ of the total injuries reported occurred while using a public vehicle (school bus, paratransit, and public bus) (Rotko, 2005). These findings indicate that more injuries occur while using a lift as opposed to a ramp. However, no information exists regarding how the injuries were sustained.

Frost and Bertocci (2006) investigated wheelchair related incident reports associated with LATV usage from 2002 to 2005 . These reports were completed by bus operators and include both categorical and narrative data. Eighty-three incidents were found. Most incidents occurred when the bus was stopped (73.2\%) but more importantly, $59.3 \%$ of the incidents occurred during ingress or egress while wheelchair passengers 
were using the bus lift/ramp. Twelve of these incidents resulted in injury. These findings indicate that adverse incidents are more likely to occur during ingress or egress (Frost and Bertocci, 2006).

The limitations of these two studies are associated with the methodological approaches. While surveys may be considered to be the most comprehensive method of gathering frequency of wheelchair user injury data, they are still subject to measurement error and can be influenced by the respondents (Songer, 2004). Transit agency records are typically limited in the details surrounding the reported injury. Although the injury data may have been over or underreported, the findings from Rotko (2005) and Frost (2006) imply an increase in injury risk during ingress/egress. Further investigation of factors that may contribute to adverse incidents is needed to gain a better understanding of injury causation and difficulty experienced by the wheelchair passenger during ingress and egress.

\section{E. Existing Design Guidelines For Ramps}

The ADA mandates design guidelines for wheelchair ramps for public transit vehicles. This legislation is encoded in 49 Code of Federal Regulations (CFR) Part 38 titled “Americans with Disabilities Act (ADA) Accessibility Specifications for Transportation Vehicles" (49 CFR Part 38, 2001). The ADA requires that transit agencies equip their vehicles with lifts and ramps to ensure access to transportation services for persons with disabilities. The Federal Transit Administration (FTA) also regulates 
guidelines specifically for accessible transit vehicle providers. These specifications titled "Guideline Specifications for Transit Vehicle Ramps" are in compliance with 49 CFR Part 38 (FTA, 1992). Manufacturers must adhere to ADA and FTA requirements when designing accessible transit ramps.

\section{Ramp Specifications}

ADA ramp specification requirements for accessible transit vehicles are outlined below (49 CFR Part 38, 2001 and FTA, 1992).

a. Design Load. Ramps 30 inches in length or greater must be able to accommodate loads up to 600 pounds when applied at the centroid of the ramp and distributed over an area of 26 inches by 26 inches. Ramps less than 30 inches in length must be able to accommodate loads up to 300 pounds. All ramps must be designed with a safety factor of 3 based on the ultimate strength of the material.

b. Ramp Surface and Width. The ramp surface must be continuous and slip resistant. The surface material cannot exceed $1 / 4$ inch in height. In addition, the surface must be 30 inches in width and be able to accommodate common wheelchairs. Common wheelchairs are defined as three-wheeled (scooters) or four-wheeled mobility devices (manual and power wheelchairs) with maximum dimensions of 30 inches in width and 48 inches in length.

c. Ramp Threshold. The ramp edge associated with the transition from the outer 
surface terrain to the ramp surface may be left without edge treatment for vertical gaps up to $1 / 4$ inch. For vertical gap heights greater than $1 / 4$ inch (but less than $1 / 2$ inch) the ramp edge must be beveled with a slope no greater than 1:2.

d. Ramp Slope. The ramp slope is the ratio of vertical length to horizontal length and is the gradient of ascent/descent for wheelchair passengers. The slope must not exceed a ratio of 1:4 when the ramp is deployed to ground level. The slope must not exceed 1:6 when the ramp is deployed to a 6 in. curb height.

\section{e. Other Ramp Specifications. Ramps must have 2 in. side barriers to prevent} wheelchair wheels from leaving the surface of the ramp. Also, the ramp must be firmly attached to the vehicle and must not exceed a 5/8 in. maximum gap between the ramp and the vehicle floor space when deployed.

\section{F. Organizations Associated With Transit Vehicle Accessibility}

In addition to the ADA and FTA regulations, there are groups and organizations in existence on local, regional, and national levels that are dedicated to assuring continual development of transit vehicle guidelines to meet the needs for persons with disabilities. As previously mentioned, the NCD and Project ACTION are groups that help bridge the gap of communication between the disability population and transit providers in order to improve transportation safety. Also, transit agencies such as the Transit Authority of 
River City (TARC, Louisville, KY) may have a local disability advisory group to help address disability issues and suggest improvements to better serve persons with disabilities.

\section{G. Summary}

These studies indicate that wheelchair passengers experience a substantial number of incidents and injuries during ingress and egress. However, these studies do not provide specific information describing the factors that contribute to incidents on public transit buses during ingress and egress, or factors that may influence injury risk. In this study, wheelchair ingress/egress activities on public transit buses were reviewed by wheelchair type, ramp extension level, wheelchair orientation on ramp, and exterior surface terrain in order to assess wheelchair passenger difficulty and incidents. Results from video surveillance footage analysis and literature were utilized in the evaluation of ADA and FTA guidelines associated with wheelchair ramp design. This is the first study to retrospectively view wheelchair ingress and egress activities using transit agency video surveillance. 


\section{METHODS}

The purpose of this study was to characterize wheelchair ingress/egress activities on large accessible transit vehicles (LATVs) in order to evaluate the adequacy of existing ADA and FTA guidelines in terms of ramp safety and usability. All wheelchair events involved a wheelchair passenger boarding/alighting an LATV. Adverse events were defined as an event involving a wheelchair passenger difficulty or incident. Public transit video surveillance provided by the Transit Authority of River City (TARC) was examined to assess ingress and egress activities. Wheelchair ingress/egress data was collected through a review of wheelchair boarding and alighting video events and documented in a database form with limited predetermined response options. Events observed as adverse events were further analyzed and evaluated for adequacy with the current ADA and FTA legislative ramp guidelines.

\section{A. General Methodology}

\section{Study Design}

This is a retrospective, descriptive study. For Specific Aims 1 and 2, existing video footage of wheelchair ingress and egress activities were reviewed in order to characterize factors contributing to adverse events. For Specific Aim 3, adverse events 
were evaluated for ramp adequacy to the existing ADA and FTA guidelines.

\section{Study Population}

The study population included wheelchair-seated passengers who travel on TARC LATVs equipped with a video surveillance system. TARC operates 285 large public transit buses and serves 1.2 million people in the Louisville metropolitan area. TARC estimates 200-250 wheelchair boardings per week (TARC). Posted notices informed LATV riders of the surveillance program. IRB approval was obtained by the University of Louisville review board to gain access to the video surveillance footage (IRB\# 170.07).

\section{$\underline{\text { 3. Sample Size }}$}

TARC operates approximately 285 LATVs, and has estimated 200-250 wheelchair boardings per week. Twenty-three of these LATVs are equipped with video surveillance systems. All camera-equipped LATVs have kneeling capabilities and have ramps with a fold-out mechanism. Digital video recorders (DVRs) were viewed $1-2$ times per week. A conservative video capture of wheelchair boardings estimate was 2.25 boardings per week, or 9 boardings per month. 108 videos of wheelchair boardings were analyzed from August 2007 to May 2008.

\section{TARC Video Surveillance System}

Video surveillance footage of wheelchair ingress/egress events on LATVs was obtained from August 2007 to May 2008. Twenty-three LATVs were equipped with GE 
MobileView III Video Surveillance System ${ }^{\circledR}$ (GE Security, Bradenton, FL). This system records digital video images at a rate of 30 frames per second and is reduced to 5-6 frames per second for each individual camera. These images have 640x480 pixel resolution.

a. Video/Audio Storage. The video and audio footage was logged onto a $120 \mathrm{~GB}$ digital video recorder (DVR), located in the LATV storage compartment, and recorded continuously in a loop for up to 30 hours. Digital video images were encoded with the respective LATV ID number, camera ID, time, and date for reference. The DVR is an interchangeable storage disk device, and can be removed from the LATV for further review. The DVRs can be inserted into a docking station, which allows the viewer to upload video and audio footage, and record video clips using video reader software.

b. Camera Setup. Each LATV was equipped with at least 4 cameras, all located inside the LATV to capture the interior and the entrance/exit doors. A supplemental fifth forward-facing camera may or may not be able to view the street from the interior side of the LATV windshield. One camera was directed at the front door to capture all wheelchair ingress/egress events. This camera view included the front door, access ramp, and 3-4 feet outside the LATV. Figure 1 shows the camera positions and their view projections. 


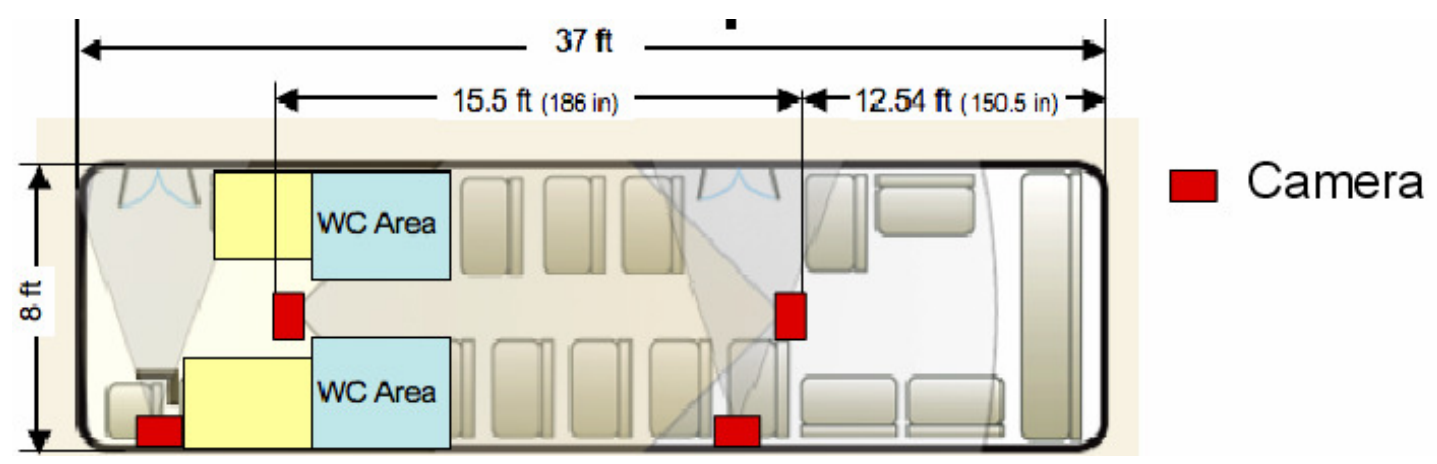

FIGURE 1 - 40 ft. TARC LATV Camera Setup

B. Specific Aim 1: Characterize adverse wheelchair-related ingress/egress events by type of event, wheelchair type, environmental conditions, and outer terrain surface types

\section{Obtaining Video Surveillance Footage}

A viewing station, similar to that used at TARC, was set up in the Injury Risk Assessment and Prevention Laboratory (Department of Mechanical Engineering, University of Louisville) to view and record video footage. The viewing station included the GE Mobile View III Docking Station, video viewing software packages, an external hard drive, and a PC to view and run software applications. DVRs were removed from the LATVs and obtained from the TARC Safety Office 2-3 times per month. Daily variation in LATV routes provided footage from a cross-section of LATV routes. Sequenced DVR selection prevented duplication from previous footage selections.

\section{Wheelchair Ingress/Egress Event Video Capture}

DVRs acquired from TARC were viewed weekly using GE Wave Reader 3.1 viewing software. Ingress/Egress events involving wheelchair-seated passengers were 
captured and recorded, and saved onto an external hard drive. Information regarding the recorded wheelchair ingress/egress events was marked onto a data log sheet indicating the tracking file number, LATV ID, date of the event, and start/stop times of the event for reference.

C. Specific Aim 2: Characterize adverse wheelchair-related ingress/egress events by type of event, wheelchair type, environmental conditions, and outer terrain surface types

\section{$\underline{1 . \text { Ingress/Egress Variables }}$}

A preliminary review of 10 previously recorded videos was performed to observe and characterize activities during ingress/egress. Operationalized definitions were established based on this preliminary review and a review of related studies. Table I shows ingress/egress variables that were identified and defined. 
TABLE I

INGRESS/EGRESS VARIABLE DEFINITIONS

\begin{tabular}{|c|c|c|}
\hline$\underline{\text { Variables }}$ & Operationalized Definition & $\begin{array}{l}\text { Response } \\
\text { Options }\end{array}$ \\
\hline $\begin{array}{l}\text { Wheelchair } \\
\text { type }\end{array}$ & $\begin{array}{l}\text { The type of wheelchair being used by the } \\
\text { wheelchair-seated passenger during the event. } \\
\text { Typical wheelchair types include manual } \\
\text { wheelchairs, power wheelchairs, and scooters. }\end{array}$ & $\begin{array}{l}1=\text { manual, } \\
2=\text { power } \mathrm{WC} \\
3=\text { scooter } \\
4=\text { other }\end{array}$ \\
\hline Gender & The gender of the wheelchair-seated passenger. & $\begin{array}{l}1=\text { male } \\
2=\text { female }\end{array}$ \\
\hline $\begin{array}{l}\text { Weather } \\
\text { Conditions }\end{array}$ & $\begin{array}{l}\text { The driving conditions during the event. The best } \\
\text { views indicating driving conditions are the front } \\
\text { door camera view and the street camera view. }\end{array}$ & $\begin{array}{l}1=\text { sunny, } \\
2=\text { overcast, } \\
3=\text { rainy, } \\
\text { 4=snowy, } \\
\text { 5=cannot } \\
\text { determine }\end{array}$ \\
\hline $\begin{array}{l}\text { Ingress: } \\
\text { start/stop } \\
\text { time of } \\
\text { process }\end{array}$ & $\begin{array}{l}\text { The period of time beginning when the front wheels } \\
\text { of the wheelchair touch the ramp and ending when } \\
\text { the rear wheels are off the ramp or fully leveled with } \\
\text { the LATV. }\end{array}$ & Time (seconds) \\
\hline $\begin{array}{l}\text { Egress: } \\
\text { start/stop } \\
\text { time of } \\
\text { process }\end{array}$ & $\begin{array}{l}\text { The period of time beginning when the front wheels } \\
\text { of the wheelchair touch the ramp and ending when } \\
\text { the rear wheels are off of the ramp. }\end{array}$ & Time (seconds) \\
\hline $\begin{array}{l}\text { Ramp } \\
\text { extension }\end{array}$ & $\begin{array}{l}\text { The ramp allows the wheelchair-seated passenger to } \\
\text { board/exit to/from LATV. The ramp, when fully } \\
\text { extended, should be flush with the outside surface } \\
\text { terrain from which the wheelchair-seated passenger } \\
\text { is entering/exiting. Beeping sounds indicate the } \\
\text { ramp being extended. }\end{array}$ & $\begin{array}{l}1=\text { yes, } \\
2=\text { no, } \\
3=\text { cannot } \\
\text { determine }\end{array}$ \\
\hline $\begin{array}{l}\text { Ramp } \\
\text { extension } \\
\text { level }\end{array}$ & $\begin{array}{l}\text { The level at which ramp was extended. Typically, } \\
\text { the ramp is extended to street level or sidewalk level. }\end{array}$ & $\begin{array}{l}1=\text { street } \\
2=\text { sidewalk }\end{array}$ \\
\hline
\end{tabular}




\begin{tabular}{|c|c|c|}
\hline$\underline{\text { Variables }}$ & Operationalized Definition & $\begin{array}{l}\text { Response } \\
\underline{\text { Options }}\end{array}$ \\
\hline $\begin{array}{l}\text { Outside } \\
\text { surface } \\
\text { terrain }\end{array}$ & $\begin{array}{l}\text { The outer surface terrain is the surface the } \\
\text { wheelchair is in contact with either prior to boarding } \\
\text { the ramp or after exiting the ramp. }\end{array}$ & $\begin{array}{l}\text { 1=smooth } \\
\text { sidewalk, } \\
\text { 2=uneven } \\
\text { sidewalk, } \\
\text { 3=dirt/grass, } \\
\text { 4=gravel, } \\
\text { 5=pavement, } \\
\text { 6=cannot } \\
\text { determine }\end{array}$ \\
\hline $\begin{array}{l}\text { Wheelchair } \\
\text { entrance } \\
\text { orientation } \\
\text { on ramp }\end{array}$ & $\begin{array}{l}\text { The direction of movement (relative to the } \\
\text { wheelchair-seated passenger) used to enter the } \\
\text { LATV. The method of boarding an LATV for a } \\
\text { wheelchair-seated passenger is either by a forward } \\
\text { or backward motion with their wheelchair. }\end{array}$ & $\begin{array}{l}1=\text { backward, } \\
2=\text { forward }\end{array}$ \\
\hline $\begin{array}{l}\text { Assistance } \\
\text { used to } \\
\text { board/exit }\end{array}$ & $\begin{array}{l}\text { Indicate whether or not the wheelchair-seated } \\
\text { passenger used assistance to board/exit the LATV, } \\
\text { i.e. was help provided by either pushing or pulling } \\
\text { the wheelchair up/down the ramp? }\end{array}$ & $\begin{array}{l}1=y e s, \\
2=\text { no }\end{array}$ \\
\hline $\begin{array}{l}\text { Assistance } \\
\text { provided } \\
\text { by whom }\end{array}$ & $\begin{array}{l}\text { If the wheelchair-seated passenger received } \\
\text { assistance to enter/exit the LATV, who assisted? } \\
\text { Operators can be quickly identified by uniform. } \\
\text { Assistants of the wheelchair-seated passenger can be } \\
\text { identified as persons who stay close to the } \\
\text { wheelchair-seated passenger and will board/exit at } \\
\text { the same time. }\end{array}$ & $\begin{array}{l}1=\text { operator } \\
2=\text { assistant } \\
3=\text { other }\end{array}$ \\
\hline Incident & $\begin{array}{l}\text { Events during which the wheelchair tipped and/or } \\
\text { passenger fell from wheelchair, wheelchair and/or } \\
\text { passenger impacted LATV door/frame or other } \\
\text { object while wheelchair was in contact with ramp, or } \\
\text { a wheelchair component broke/dropped. }\end{array}$ & $\begin{array}{l}1=y e s, \\
2=\text { no }\end{array}$ \\
\hline $\begin{array}{l}\text { Passenger } \\
\text { difficulty }\end{array}$ & $\begin{array}{l}\text { Events involving } 2 \text { or more maneuvering attempts } \\
\text { by the wheelchair-seated passenger, and/or an } \\
\text { impact (bump) with an LATV component(s). }\end{array}$ & $\begin{array}{l}1=y e s, \\
2=\text { no }\end{array}$ \\
\hline
\end{tabular}




\section{Video Database/Data Recording}

Recorded video footage was analyzed using GE's QuickWave viewing software.

Figure 2 shows the output of the GE QuickWave software utilized for video analysis which included playback features, frame-by-frame viewing options, and single or multiple camera view selection. To capture and characterize all the ingress/egress activities and incorporate the operationalized definitions for wheelchair ingress/egress variables (refer to Appendix I), a database was created using database application software FileMaker Pro version 8.5.

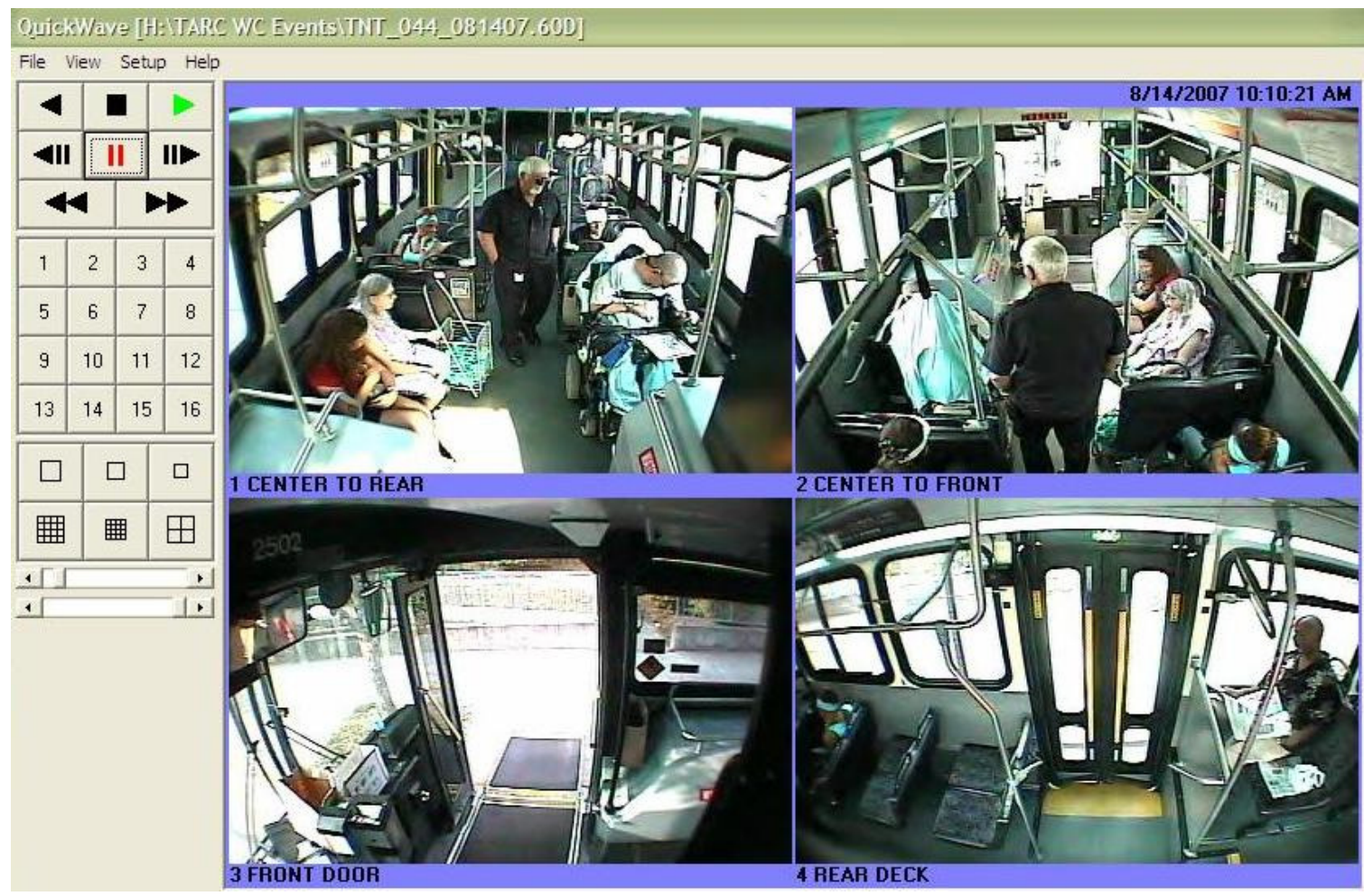

FIGURE 2 - Output of GE QuickWave Software 


\section{$\underline{\text { 3. Video Data Analysis }}$}

All ingress/egress variables (Table 2) were analyzed based on frequencies. Adverse events were assessed both qualitatively and quantitatively with the previously defined variables. Descriptive statistics for each variable were calculated using MS Excel 2004 for Mac.

D. Specific Aim 3: Evaluate the adequacy of current legislative guidelines (Americans with Disabilities Act and the Federal Transit Administration) as they relate to wheelchair $\underline{\text { ramp design }}$

For Specific Aim 3, the subset of adverse events was further examined to assess adequacy of ADA and FTA guidelines relating to passenger difficulty or an incident. Human factors (operator and/or passenger error) were also examined.

\section{Variables for Evaluating Adequacy of Current Legislative Guidelines}

Variables were categorized into one of three groups: ramp variables (width, threshold, side barriers, and slope), LATV (any LATV component such as door, fare box, and storage compartment), or human (either wheelchair passenger or operator) factors. Each variable was examined and rated as "adequate", "not adequate", or "cannot determine" for each adverse event based on the criteria forth in Table II. 
TABLE II

VARIABLES FOR EVALUATING ADEQUACY OF CURRENT LEGISLATIVE

GUIDELINES

\begin{tabular}{|c|c|c|}
\hline Variables & Adequate & Not Adequate \\
\hline Width & $\begin{array}{l}\text { Wheelchair passenger was able to } \\
\text { successfully align wheelchair } \\
\text { between ramp side barriers } \\
\text { without repeated maneuvering. }\end{array}$ & $\begin{array}{l}\text { Repeated ( } 2 \text { or more) maneuvers } \\
\text { performed by wheelchair passenger } \\
\text { to align wheelchair within side } \\
\text { barriers }\end{array}$ \\
\hline Slope & $\begin{array}{l}\text { Wheelchair passenger did not } \\
\text { appear to have difficulty with the } \\
\text { incline of the ramp (W/C } \\
\text { passenger was able to } \\
\text { successfully traverse slope of } \\
\text { ramp without repeated } \\
\text { maneuvering due to incline }\end{array}$ & $\begin{array}{l}\text { Wheelchair passenger appeared to } \\
\text { have difficulty with the incline of } \\
\text { the ramp (W/C passenger could not } \\
\text { successfully traverse full length of } \\
\text { ramp due to slope, requiring } \\
\text { operator to realign LATV/ramp } \\
\text { before wheelchair passenger } \\
\text { boarded/alighted, or assistance in } \\
\text { pulling/pushing wheelchair over } \\
\text { sloped ramp) }\end{array}$ \\
\hline Threshold & $\begin{array}{l}\text { Wheelchair passenger } \\
\text { successfully traversed across the } \\
\text { transition between the outer } \\
\text { terrain surface and ramp surface } \\
\text { without experiencing jolts, } \\
\text { bumps, and/or abrupt movements. }\end{array}$ & $\begin{array}{l}\text { Wheelchair experienced jolts, } \\
\text { bumps, and/or abrupt movements } \\
\text { while moving across threshold. }\end{array}$ \\
\hline Side Barriers & $\begin{array}{l}\text { Side barriers contained } \\
\text { wheelchair within ramp surface } \\
\text { area }\end{array}$ & $\begin{array}{l}\text { Side barriers did not contain } \\
\text { wheelchair within ramp surface area } \\
\text { (wheelchair breaches side barrier(s) } \\
\text { during ramp ascent or descent) }\end{array}$ \\
\hline $\begin{array}{l}\text { Wheelchair- } \\
\text { seated } \\
\text { Passenger }\end{array}$ & $\begin{array}{l}\text { Wheelchair passenger maintains } \\
\text { smooth control of the wheelchair } \\
\text { (wheelchair passenger } \\
\text { successfully traverses ramp } \\
\text { without error). }\end{array}$ & $\begin{array}{l}\text { Wheelchair passenger did not } \\
\text { maintain proper alignment with the } \\
\text { ramp, required multiple ( } 2 \text { or more) } \\
\text { maneuvers (Passenger difficulty } \\
\text { appeared to be due to a mistake } \\
\text { made the wheelchair passenger } \\
\text { rather than a poorly designed or } \\
\text { malfunctioning component of the } \\
\text { ramp) }\end{array}$ \\
\hline
\end{tabular}




\begin{tabular}{|l|l|l|}
\hline Variables & Adequate & Not Adequate \\
\hline \multirow{3}{*}{ Operator } & $\begin{array}{l}\text { Operator successfully parks the } \\
\text { LATV parallel to the street, clear } \\
\text { of environmental obstacles, and } \\
\text { deploys the ramp (level with) } \\
\text { outer terrain surface. }\end{array}$ & $\begin{array}{l}\text { Operator does not deploy ramp } \\
\text { evenly flush to the outer terrain } \\
\text { surface. (LATV not parked parallel } \\
\text { to street (e.g. at sidewalk ramp), one } \\
\text { or more environmental barrier(s) } \\
\text { interfere w/wheelchair passenger's } \\
\text { ability to successfully align } \\
\text { wheelchair with ramp, and/or ramp } \\
\text { not deployed level to outer terrain } \\
\text { surface). }\end{array}$ \\
\hline $\begin{array}{l}\text { LATV } \\
\text { Component }\end{array}$ & $\begin{array}{l}\text { Wheelchair and/or passenger does } \\
\text { not impact the LATV door and/or } \\
\text { other LATV components }\end{array}$ & $\begin{array}{l}\text { Wheelchair and/or passenger impact } \\
\text { the LATV door and/or other LATV } \\
\text { components }\end{array}$ \\
\hline
\end{tabular}

\section{Data Analysis: Evaluating Adequacy of Current Legislative Guidelines}

Each adverse event video was reviewed and abstracted into a brief narrative. This data was used to rate each guideline as adequate, not adequate or cannot determine for an adverse event. Descriptive statistics for each variable assessment were calculated using MS Excel 2004 for Mac. 


\section{Results}

\section{A. Specific Aim 1: Wheelchair Ingress and Egress Characteristics}

\section{$\underline{1 . \text { General Information }}$}

During the study period, 108 wheelchair boarding events (consisting of 108 ingress and 108 egress events) were recorded. Each ingress and each egress was analyzed as a separate event. All events in the sample size met the inclusion criteria and involved wheelchair-seated passengers who used a wheelchair as their primary means of mobility. In addition, all events observed encompassed the entire process of both ingress and egress (no partial ingress or egress events were included).

As shown in Table III, the most common type of wheelchair observed was the power wheelchair $(67.59 \%, \mathrm{n}=73)$, followed by manual wheelchairs $(26.85 \%, \mathrm{n}=29)$, and scooters $(5.56 \%, \mathrm{n}=6)$. The gender distribution of the wheelchair-seated passengers was $61.11 \%(n=66)$ male and $38.89 \%(n=42)$ female. Driving conditions were primarily associated with sunny weather $(83.33 \%, \mathrm{n}=90)$. There were no ingress/egress events during snowy weather. 
TABLE III

WHEELCHAIR TYPE, PASSENGER GENDER, AND DRIVING CONDITIONS FOR

WHEELCHAIR INGRESS/EGRESS EVENTS (N=108)

\begin{tabular}{|ccc|}
\hline & No. of Events & Percentage \\
\hline & Wheelchair Type & \\
Manual Wheelchair & 29 & $26.85 \%$ \\
Power Wheelchair & 73 & $67.59 \%$ \\
Scooter & 6 & $5.56 \%$ \\
\hline \multicolumn{1}{c}{ Gender of Wheelchair Passenger } \\
Male & 66 & \\
Female & 42 & $61.11 \%$ \\
& & $38.89 \%$ \\
\hline Sunny & Driving Conditions & \\
Overcast & 90 & $83.33 \%$ \\
Rainy & 5 & $4.63 \%$ \\
Snowy & 3 & $2.78 \%$ \\
Nighttime & 0 & $0.00 \%$ \\
Cannot Determine & 10 & $9.26 \%$ \\
& 0 & $0.00 \%$ \\
\hline
\end{tabular}

\section{Ingress and Egress Activities}

a. Ingress Activities. The average time elapsed from when the front caster wheels contacted the ramp until the rear wheels were fully leveled with the LATV interior surface during all ingress events (including adverse events) was $8.6 \pm 12.7$ seconds. As shown in Table 4, the most frequent wheelchair orientation used to ascend the ramp was forward-facing $(73.15 \%, n=79)$ versus rear-facing $(26.85 \%, n=29)$. The ramp was 
extended to sidewalk level in $87.04 \%$ of boardings, and to street level during $11.11 \%$ $(n=12)$ of boardings. In approximately $2 \%(n=2)$ of boardings, ramp extension to sidewalk or to street level could not be determined. The surface terrain adjacent to the ramp was primarily smooth concrete for $68.52 \%(n=74)$ of boardings, followed by uneven concrete/pavement $(14.81 \%, \mathrm{n}=16)$, smooth pavement $(7.41 \%, \mathrm{n}=8)$, and grass/dirt $(7.41 \%, \mathrm{n}=8)$. Approximately $86 \%(\mathrm{n}=93)$ of the wheelchair boardings did not involve assistance, while the remaining involved passenger assistance. (Table IV).

b. Egress Activities. The average time to descend the ramp from when the front wheels were at the top of the ramp until the rear wheels were fully leveled with the outer terrain surface during all egress events (including adverse events) was $4.12 \pm 4.64$ seconds. All egress events involved forward-facing orientation to descend the ramp. The majority of egress events involved the ramp extension onto the sidewalk level $(75 \%$, $n=81)$. The remainder of the events were associated with ramp extension to street level $(23.15 \%, n=25)$ and $1.85 \%(n=2)$ could not be determined. The surface terrain was mostly smooth concrete $(61.11 \%, \mathrm{n}=66)$, followed by uneven concrete/pavement $(20.37 \%, n=22)$, smooth pavement $(10.19 \%, n=11)$, and dirt/grass $(6.48 \%, n=7)$. In regards to passenger assistance, $17.59 \%(\mathrm{n}=19)$ of the events involved passenger assistance while the remainder did not require assistance. These results are summarized in Table IV. 
TABLE IV

WHEELCHAIR INGRESS AND EGRESS CHARACTERISTICS

INGRESS: N=108, EGRESS: N=108

\begin{tabular}{|c|c|c|c|c|}
\hline & Ing & & Egr & \\
\hline & No. of Events & Percentage & No. of Events & Percentage \\
\hline Wheelchair Orientat & & & & \\
\hline Rear Facing & 29 & $26.85 \%$ & 0 & $0.00 \%$ \\
\hline Forward Facing & 79 & $73.15 \%$ & 108 & $100.00 \%$ \\
\hline$\underline{\text { Ramp Extension Lev }}$ & & & & \\
\hline Street & 12 & $11.11 \%$ & 25 & $23.15 \%$ \\
\hline Sidewalk & 94 & $87.04 \%$ & 81 & $75.00 \%$ \\
\hline Cannot Determine & 2 & $1.85 \%$ & 2 & $1.85 \%$ \\
\hline$\underline{\text { Surface Terrain }}$ & & & & \\
\hline Smooth Concrete & 74 & $68.52 \%$ & 66 & $61.11 \%$ \\
\hline $\begin{array}{c}\text { Uneven Concrete/ } \\
\text { Pavement }\end{array}$ & 16 & $14.81 \%$ & 22 & $20.37 \%$ \\
\hline Dirt/Grass & 8 & $7.41 \%$ & 7 & $6.48 \%$ \\
\hline Gravel & 0 & $0.00 \%$ & 0 & $0.00 \%$ \\
\hline Smooth Pavement & 8 & $7.41 \%$ & 11 & $10.19 \%$ \\
\hline Cannot Determine & 2 & $1.85 \%$ & 2 & $1.85 \%$ \\
\hline Assistance Provided & d/or Required & & & \\
\hline Yes & 15 & $13.89 \%$ & 19 & $17.59 \%$ \\
\hline No & 93 & $86.11 \%$ & 89 & $82.41 \%$ \\
\hline
\end{tabular}




\section{B. Specific Aim 2: Categorizing Adverse Events (Passenger Difficulty and Incidents)}

\section{$\underline{1 . \text { Frequency of Adverse Events }}$}

From the 108 ingress events and 108 egress recorded events, a subset of 26 adverse events were identified, involving either passenger difficulty or an incident. All adverse events were resolved and the wheelchair passenger successfully boarded/alighted the LATV. Weather conditions did not appear to contribute to adverse events $(n=20$, $76.9 \%)$.

During ingress, approximately $20 \%(\mathrm{n}=22)$ of the wheelchair boardings were categorized as a passenger difficulty. Recall that passenger difficulty was operationalized as multiple maneuvering attempts and/or an impact (bump) with an LATV component(s). There were no incidents recorded during ingress (Table V).

During egress, there were $3(2.78 \%)$ events associated with passenger difficulty and $1(0.93 \%)$ event that involved an incident. From the previously mentioned variables, incidents were defined as impacts, tips, and/or falls involving wheelchair/wheelchair component and/or wheelchair passenger. There was one noted incident during egress (Table V). 
TABLE V

FREQUENCIES OF PASSENGER DIFFICULTIES OR INCIDENTS

$$
(\mathrm{N}=108)
$$

\begin{tabular}{|ccc|cc|}
\hline & \multicolumn{2}{c|}{ Ingress } & \multicolumn{2}{c|}{ Egress } \\
& No. of & No. of & \\
Events & Percentage & Events & Percentage \\
$\begin{array}{c}\text { Successful } \\
\text { Ingress/Egress }\end{array}$ & 86 & $79.63 \%$ & 104 & $96.30 \%$ \\
Events & & $0.00 \%$ & 1 & $0.93 \%$ \\
Incident & 0 & $20.37 \%$ & 3 & $2.78 \%$ \\
Difficulty & 22 & & & \\
\hline
\end{tabular}

\section{Adverse Events By Wheelchair Type}

Both wheelchairs and scooters were observed during adverse events involving a passenger difficulty or incident. However, power wheelchairs were most frequently observed. During ingress, approximately $59 \%(n=13)$ of adverse events involved power wheelchairs, followed by manual wheelchairs $(31.82 \%, \mathrm{n}=7)$, and scooters $(9 \%, \mathrm{n}=2)$. During egress, all adverse events involved power wheelchairs (Figure 3). 
- Manual Wheelchair $\mathbb{Q}$ Power Wheelchair $\square$ Scooter

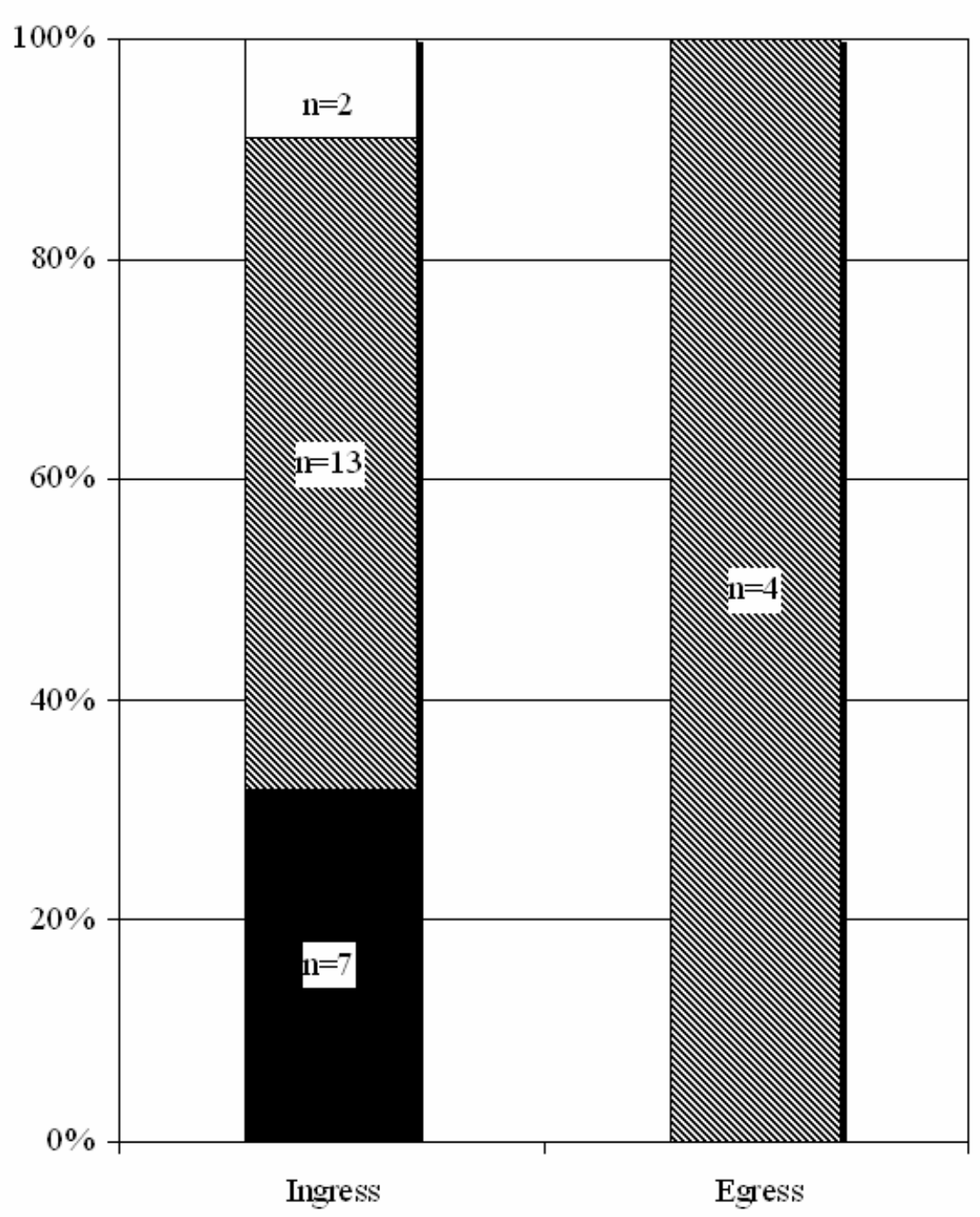

FIGURE 3 - Adverse Events By Wheelchair Type

\section{Adverse Events By Ramp Extension Level}

The ramp extension level during passenger difficulty or incidents was primarily onto the sidewalk. During ingress, $83.36 \%(n=19)$ of the adverse events were associated with ramp extension onto the sidewalk, while the remainder of the events involved ramp extension to street level. During egress, the majority of adverse events were associated 
with ramp extension onto the sidewalk $(75 \%, \mathrm{n}=3)$. The "other" category during the fourth egress event could not be defined as either street or sidewalk level due to either a difficulty in discerning the ramp extension level during nighttime events or the ramp was extended onto inclines that were not distinguished as a sidewalk or street (Figure 4).

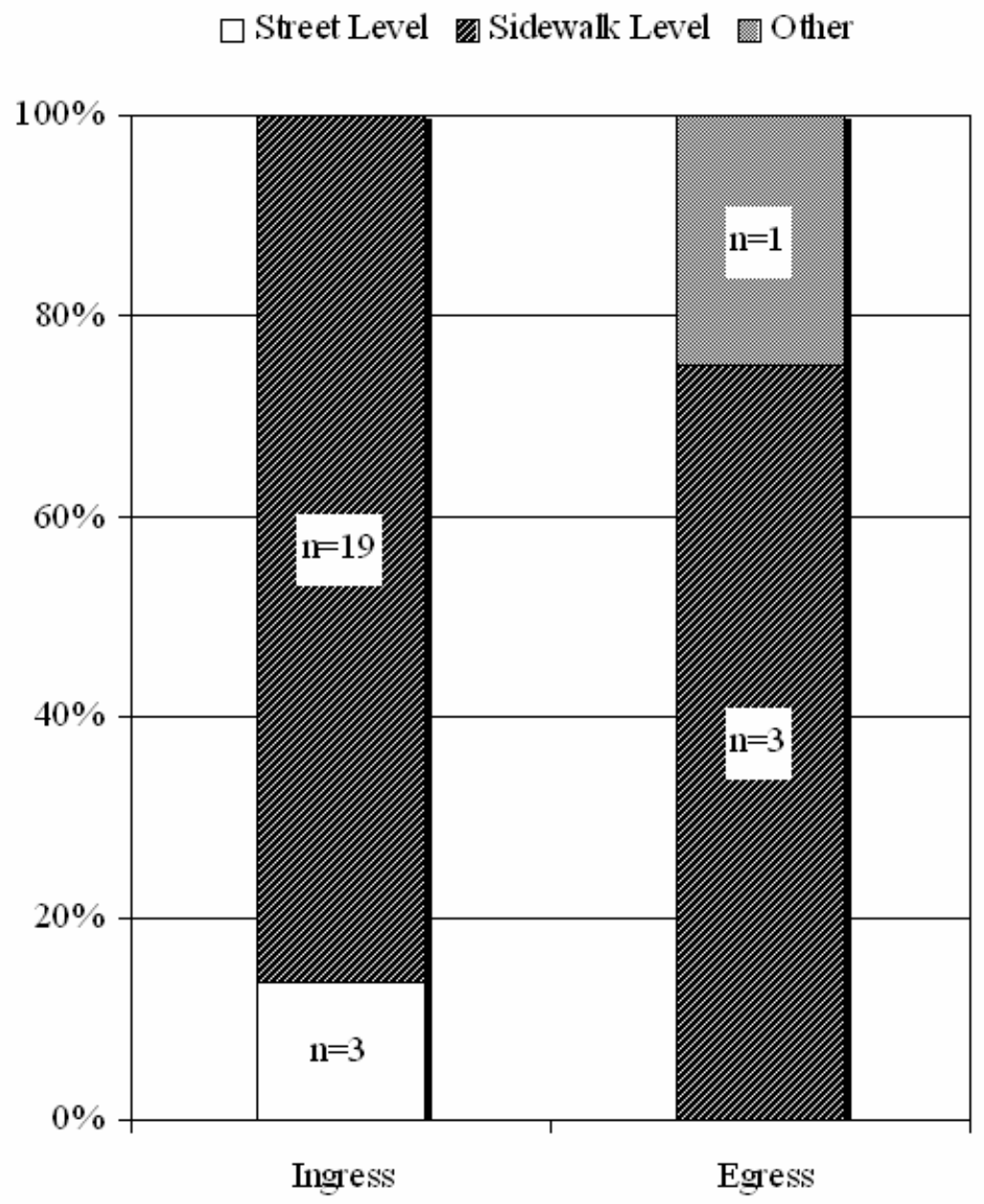

FIGURE 4 - Adverse Events by Ramp Extension Level 


\section{Adverse Events By Wheelchair Orientation}

Wheelchair orientation during adverse events involved both rear-facing and forward-facing orientation. During ingress, forward-facing orientation was used to board the LATV in $36.38 \%(\mathrm{n}=8)$ of the adverse events. Interestingly, rear-facing orientation was performed to ascend the ramp in the majority of adverse ingress events (63.64\%, $\mathrm{n}=14$ ). TARC suggests rear-facing orientation during ingress to reduce the risk of tipping (Barry Barker, TARC). All events involving passenger difficulty or an incident during egress used forward-facing orientation (Figure 5).

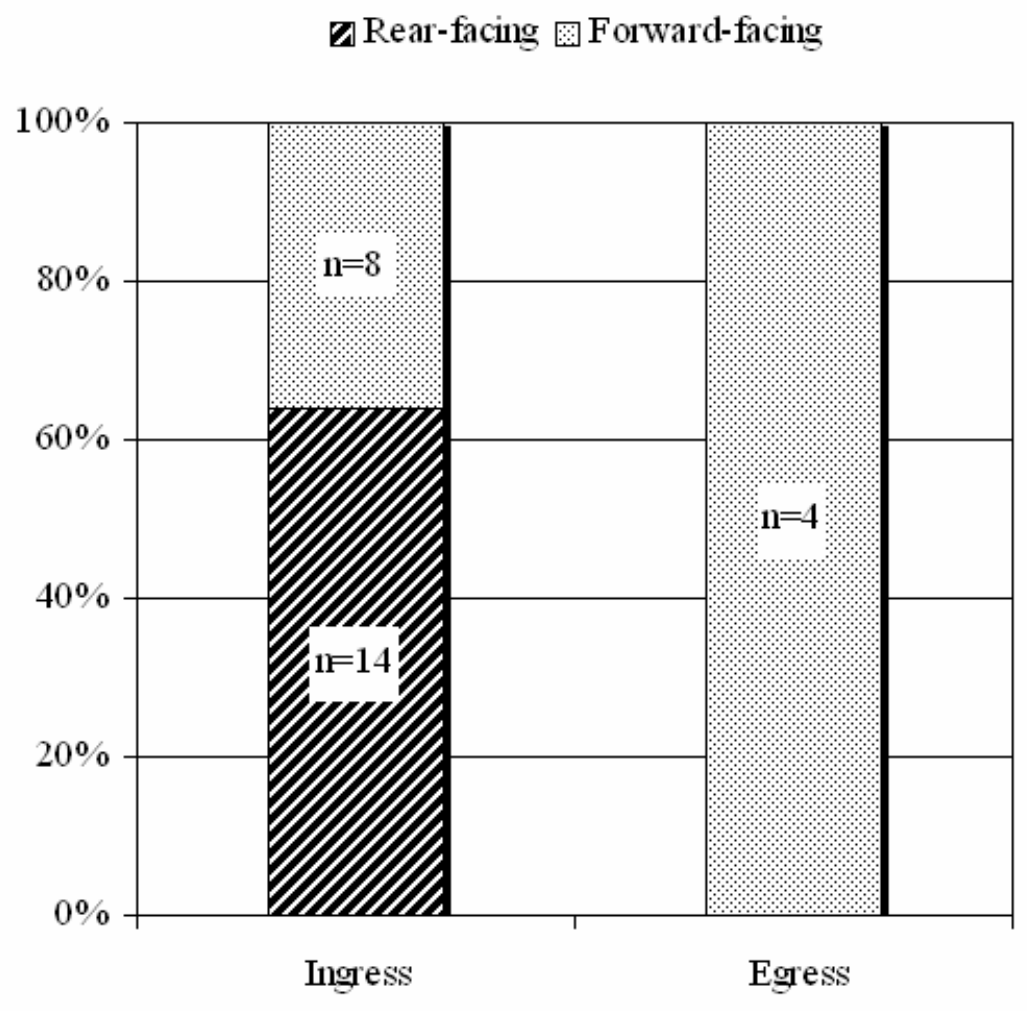

FIGURE 5 - Adverse Events By Wheelchair Orientation

\section{Adverse Event By Passenger Assistance}


Passenger assistance during adverse events involved LATV operator and other passengers providing assistance. During ingress, most of the adverse events did not require assistance by another person $(54.55 \%, \mathrm{n}=12)$. However, $36.36 \%(\mathrm{n}=8)$ involved assistance being provided by the LATV operator and $9 \%(n=2)$ involved assistance being provided by another LATV passenger. During egress, the majority of adverse events involved assistance by the LATV operator $(75 \%, \mathrm{n}=3)$ and the remainder involved passenger assistance provided by another passenger $(25 \%, n=1)$ (Figure 6).

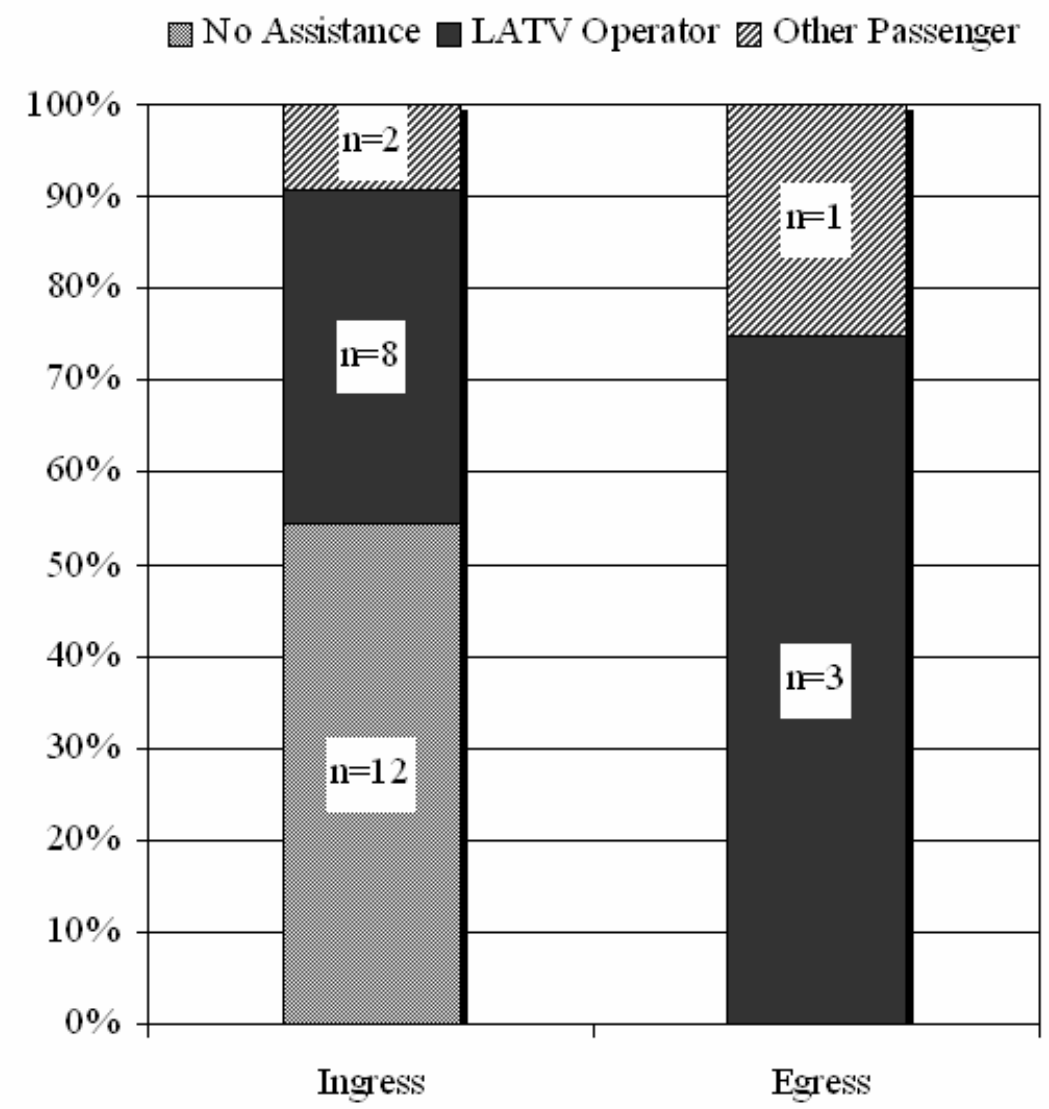

FIGURE 6 - Adverse Events By Type of Assistance Provided 
C. Specific Aim 3: Evaluate the adequacy of current legislative guidelines (Americans with Disabilities Act and the Federal Transit Administration) as they relate to wheelchair $\underline{\text { ramp design }}$

Twenty-two adverse ingress events and four adverse egress events were analyzed to determine which ramp related design variable(s) appeared to contribute to its classification as either a passenger difficulty or an incident. Adverse events may or may not have multiple variables that contributed to the passenger difficulty or incident. Each variable was assessed in terms of "adequate," "not adequate," or "cannot determine" in association with the ramp, LATV, and human factor(s). The assessment of each adverse event based on current legislative guidelines can be reviewed in Appendix II and III.

\section{$\underline{1 . \text { Adverse Ingress Events }}$}

During adverse ingress events, the primary ramp design variables contributing to either a passenger difficulty or incident were the threshold located at the bottom of the $\operatorname{ramp}(n=7,31.82 \%)$, ramp slope $(n=7,31.82 \%)$, and ramp width $(n=4,18.18 \%)$. Ramp side barriers did not contribute to the adverse ingress events. Wheelchair/wheelchair passenger impacts into LATV components such as the LATV door contributed to $40.91 \%$ $(n=17)$ of adverse ingress events. Difficulty maneuvering the wheelchair by the passenger (wheelchair-seated passenger) was associated with $77.27 \%(\mathrm{n}=17)$ of adverse ingress

events, while operator factor contributed to $27.27 \%(n=6)$ of the ingress events (Table VI). 
TABLE VI

ADEQUACY OF RAMP RELATED DESIGN VARIABLES DURING ADVERSE INGRESS EVENTS BASED ON CURRENT AMERICANS WITH DISABILITES ACT (ADA) SPECIFICATIONS

$(\mathrm{N}=22)$

\begin{tabular}{|c|c|c|c|c|c|c|}
\hline Variable & \multicolumn{2}{|c|}{ Adequate } & \multicolumn{2}{|c|}{ Not Adequate } & \multicolumn{2}{|c|}{$\begin{array}{c}\text { Cannot } \\
\text { Determine }\end{array}$} \\
\hline$\underline{\operatorname{Ramp}}$ & No. & $\%$ & No. & $\%$ & No. & $\%$ \\
\hline Width & 17 & $77.27 \%$ & 4 & $18.18 \%$ & 1 & $4.55 \%$ \\
\hline Threshold & 13 & $59.09 \%$ & 7 & $31.82 \%$ & 2 & $9.09 \%$ \\
\hline Side Barriers & 20 & $90.91 \%$ & 0 & $0.00 \%$ & 2 & $9.09 \%$ \\
\hline Slope & 12 & $54.55 \%$ & 7 & $31.82 \%$ & 3 & $13.64 \%$ \\
\hline$\frac{\text { LATV }}{\text { LATV Component }}$ & 11 & $50.00 \%$ & 9 & $40.91 \%$ & 2 & $9.09 \%$ \\
\hline $\begin{array}{l}\quad \underline{\text { Human }} \\
\text { Wheelchair-seated passenger } \\
\text { Operator Factor } \\
\text { (ramp deployment) }\end{array}$ & 16 & $18.18 \%$ & 17 & $77.27 \%$ & 1 & $4.55 \%$ \\
\hline
\end{tabular}

\section{Adverse Egress Events}

During adverse egress events, the primary contributing factor observed in all of the events $(n=4)$ was associated with the passenger experiencing difficulty maneuvering his/her wheelchair. As shown in Table VII, the width, threshold, slope, LATV component obstruction, and operator were not observed as factors associated with adverse egress events. 
TABLE VII

ADEQUACY OF RAMP RELATED DESIGN VARIABLES DURING ADVERSE

EGRESS EVENTS BASED ON CURRENT AMERICANS WITH DISABILITES ACT

(ADA) SPECIFICATIONS

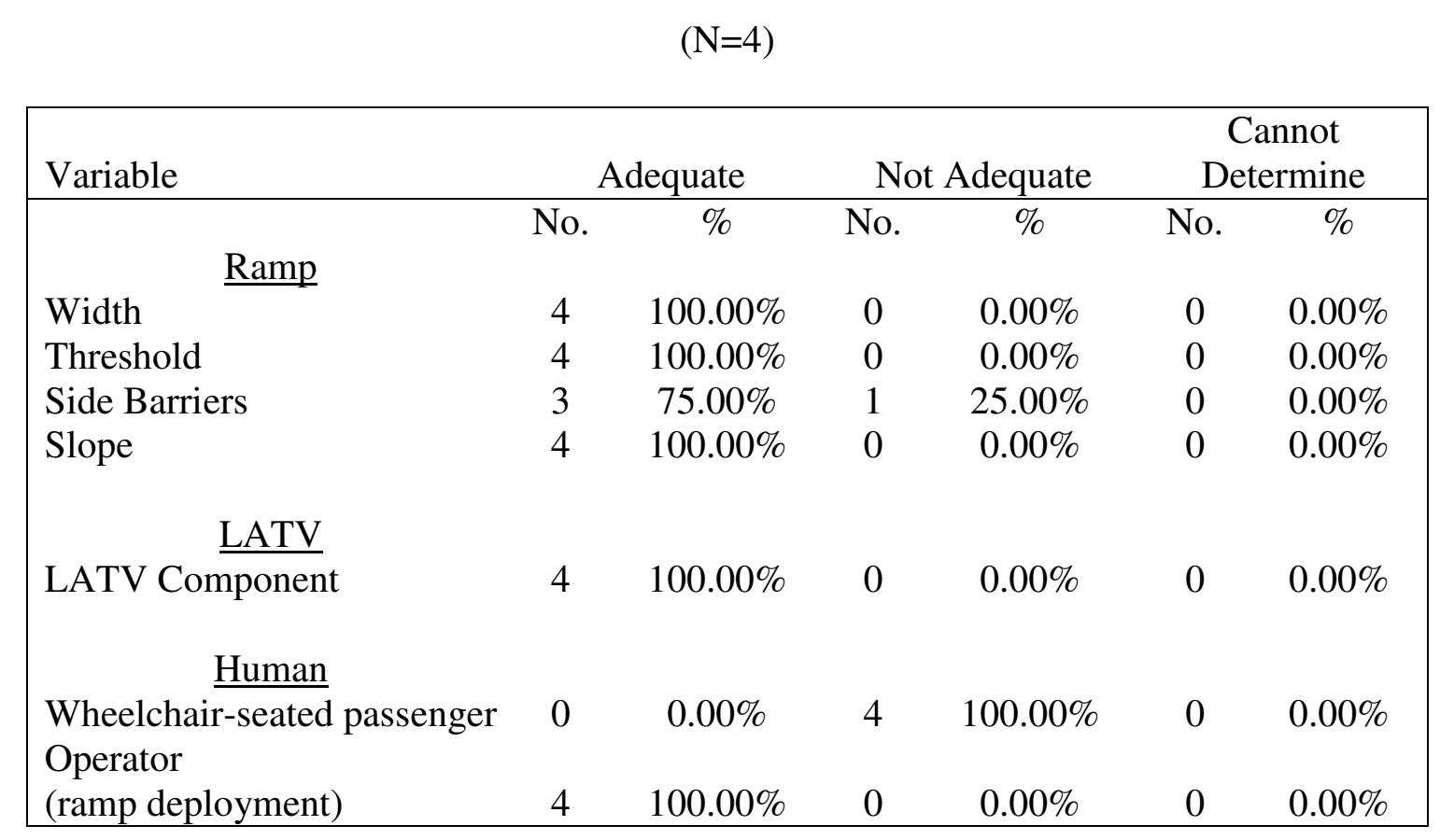

The only observed incident occurred during egress. During this event, the ramp was extended to street level and the surface terrain was smooth concrete. A passenger using a power wheelchair drove close to the right edge of the ramp while descending; driving the right front caster over the right side barrier of the ramp. The LATV operator assisted the passenger by tilting and pulling the wheelchair to the left to raise the caster back on to the ramp. The LATV operator then re-aligned the wheelchair and guided the wheelchair-seated passenger down the ramp until the passenger was safely off the ramp. In this case, the ramp side barrier failed to prevent the wheelchair caster from keeping contact with the ramp. 


\section{DISCUSSION}

There is little information available regarding wheelchair ingress and egress activities in public transit vehicles, specifically LATVs. The limited number of studies that exist indicate that public transit buses are one of the safest modes of travel (Shaw, 2000, Shaw 2003, Richardson, 1991). The intent of this study was to characterize wheelchair-seated passenger LATV ingress/egress events in order to understand which ramp related variables may be involved in adverse events. Also, this study further identified adverse ingress/egress events to evaluate the adequacy of current existing ramp guidelines to which transit agency providers and transit manufacturers must adhere.

\section{$\underline{\text { A. General Ingress/Egress Activities }}$}

\section{Wheelchair Orientation}

TARC policy does not include a specified wheelchair orientation for wheelchairseated passengers for ingress/egress. However, TARC recommends that wheelchairseated passengers ascend the ramp in a rear-facing orientation during ingress. A rearfacing orientation helps to maintain the center of gravity of the wheelchair-seated passenger toward the uphill portion of the ramp and closer to the LATV, thus reducing the risk of tipping. In this study, rear-facing orientation was used by 29 (26.85\%) wheelchair 
seated passengers during 108 ingress events, and 14 (12.96\%) of these boardings were classified as an adverse event involving passenger difficulty. It was observed that wheelchair users encountered difficulty while either aligning the wheelchair at the base of the ramp, or maintaining proper alignment while ascending. Kirby et al. (Kirby, 1995) found that wheelchair users with the ability to control their wheelchair can influence the stability of their wheelchairs. Though rear-facing orientation is recommended by TARC, it may still result in passenger difficulty when boarding a LATV. Some difficulties may be caused by limited motion in the head and/or neck or limited visibility experienced when navigating rearward.

\section{Ramp Extension Level}

Ramps are an essential component of accessible transportation. NHTSA reported that $6 \%$ of injury producing activities involving wheelchair users occurred on ramps (NHTSA, 1997). In this study, the ramp extension to street level appeared to contribute to passenger difficulty in 3 of $22(13.63 \%)$ adverse ingress events. During ingress/egress, the angle of incline is greater when the ramp is extended to street level, and this increased incline may present challenges. During ingress, power wheelchairs and scooters can cause difficulty in ascending the ramp because they are large in size and heavy in weight; manual wheelchair users may have difficulty in propelling themselves up the ramp. During egress, if the ramp is too steep, a passenger not wearing a pelvic belt could be at an increased risk of falling from their wheelchair.

According to the ADA ramp specifications, the maximum ramp angle allowed is 9 degrees (1:6 slope) when the ramp is kneeled onto a 6-inch curb/sidewalk, and 14 degrees 
(1:4 slope) when the ramp is kneeled onto the street (see Figure 7 for angle reference).

The control switch to kneel the LATV must be activated before the ramp can be extended, thus ramp deployment cannot occur unless the LATV is kneeled. However, the extent of the LATV kneel is determined by the LATV operator. The kneeling height of the LATV is important because the length of the ramp is fixed. Therefore, the kneel height of the LATV is the primary influence on the ramp slope - the longer the duration of the switch is depressed, the lower the LATV height, which results in smaller ramp angles during ascent/descent. LATV kneeling and ramp configurations used in all of the camera-system equipped TARC LATVs can achieve a ramp angle range between 7 to 17 degrees. Table VIII shows the range of angles associated with kneeled LATV position and level of ramp extension. For minimally kneeled LATV heights, the measured angles exceed the ADA specifications for both street and sidewalk levels. Thus, full LATV kneeling and ramp extension onto sidewalk levels are critical in assuring ramp angles during ascent/descent that comply with ADA guidelines.

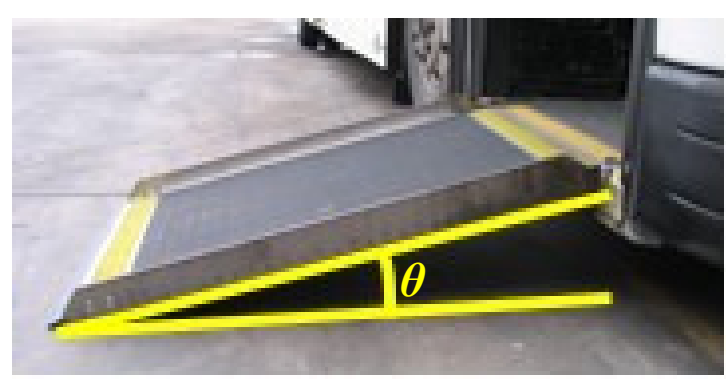

$\theta$ indicates measured LATV ramp angle

FIGURE 7 - Ramp Angle Associated With Ingress/Egress Events 
TABLE VIII

MEASURED TARC LATV RAMP ANGLES

\begin{tabular}{|lcc|}
\hline \multicolumn{1}{|c|}{$\begin{array}{c}\text { LATV height position } \\
\text { (from ground surface to } \\
\text { LATV floor) }\end{array}$} & $\begin{array}{c}\text { Sidewalk Level } \\
\text { 6-in. curb } \\
\text { (degrees) }\end{array}$ & $\begin{array}{c}\text { Street Level } \\
\text { (degrees) }\end{array}$ \\
\hline $\begin{array}{l}\text { Fully Kneeled } \\
\text { (11.5 in.) } \\
\begin{array}{l}\text { Minimally Kneeled } \\
(14 \text { in.) }\end{array}\end{array}$ & 7 & 14 \\
\hline
\end{tabular}

* Indicates angles exceeding ADA maximum ramp slope mandate (49 CFR Part 38).

\section{Assistance}

One of the main goals of ADA is to promote and increase independence for persons with disabilities. In this study, approximately $14 \%$ of ingress events involved assistance by the LATV operator, passenger assistant, or another LATV passenger. During egress, $17.59 \%$ of events involved assistance. In relation to adverse events, 10 of 22 ingress adverse events and all 4 egress adverse events involved assistance by either the LATV operator or another LATV passenger. Although some observations indicated that assistance was clearly required, there was a subset of events in which assistance was provided without inquiry. These situations may be a result of a single or combination of reasons such as general courtesy, perceived difficulty by the person providing the assistance, and/or time restrictions of the LATV operator associated with fixed routes. 


\section{B. Factors Contributing to Adverse Ingress/Egress Events}

\section{Ramp Width}

The ADA requirement for ramp width is 30 inches to accommodate common wheelchairs. Recall that a common wheelchair refers to either 3-wheeled (i.e. scooters) or 4-wheeled (i.e. manual and power wheelchairs) mobility devices which have maximum dimensions of 30 inches in width and 48 inches in length. In this study, ramp width appeared to be a contributing factor in 4 of 22 adverse ingress events. More notably, 3 of the events pertaining to ramp width involved "large" and "over-sized" wheelchairs. In one event, a manual wheelchair user experienced difficulty because the rear left wheel of her bariatric wheelchair hit the left side barrier at the bottom of the ramp while using a rear-facing orientation. The width of her wheelchair reduced the area in which she was able to maneuver. She realigned her wheelchair by moving forward and then back twice before clearing the ramp threshold. This resulted in assistance by the LATV operator (See Appendix II).

Camera equipped TARC LATVs have a ramp width of 31.5 inches which includes the interior surface width from the inner sides of the side barriers. Although compliant with the ADA, this measurement allows less than 1.5 inches of extra space total for the wheelchair user to maneuver his/her wheelchair up/down the access ramp if the wheelchair is 30 in wide. This may be an added difficulty for wheelchair users due to the limited space. Power wheelchairs and scooters, for example, may be at an increased risk of traversing side barriers while ascending the ramp in a rear-facing orientation. Items 
located beyond the width of the wheelchair such as arms, hands, and personal bags on either side of the wheelchair may contact LATV components such as the LATV door/frame and hinder the user. Moreover, bariatric or "over-sized" wheelchairs may exceed the specified "common wheelchair" dimensions resulting in even less maneuvering clearance when in contact with the ramp. Due to an increase in bariatric wheelchair, power wheelchair, and scooter use (LaPlante, 2003), it is important to address space requirement issues. Video analysis from this study suggests a need for further research regarding clearance around the LATV door, ramp width, and area around the entry/exit path.

\section{Ramp Slope and Ramp Extension}

The level of ramp extension and the extent of LATV kneeling are important factors influencing the ramp slope. As previously mentioned, when the ramp is not extended onto a sidewalk level, the angle of ascent/decent may exceed ADA specifications. In addition, the LATV operator decides what extent to kneel the LATV. If the LATV is not fully lowered, the slope may be at the maximum allowable range or may exceed ADA specifications (Table VIII). Future training of LATV operators should include ramp extension to the sidewalk in all possible wheelchair ingress and egress scenarios. Also, transit agencies should emphasize the need to fully lower the LATV to decrease the angle of ascent/descent for wheelchair passengers.

In addition to training opportunities for LATV operators, findings show that ramp extension to sidewalk level may not be sufficient to reduce the risk of adverse events involving ramp slope. In this study, 19 of 22 adverse ingress events and 3 of 4 adverse 
egress events were associated with ramp extension to the sidewalk. Ramp slope appeared to be a factor in 7 of 22 adverse ingress events in which a wheelchair passenger experienced difficulty ascending the ramp due to incline. Although adverse events that were analyzed were products of a combination of factors, findings (Table VIII) indicate that ADA specifications are not being met in the field, and this failure may contribute to increased passenger difficulty and/or incidents. Ramp design specifications can be improved by increasing ramp length to reduce the slope and to ensure safety to wheelchair passengers.

\section{Ramp Side Barriers}

The main purpose of side barriers is to prevent wheelchairs from falling from the ramp. The ADA guidelines specify a side barrier height of 2 inches as measured from the surface of the ramp. TARC LATV side barriers as shown in Figure 8 are 2 inches in height from the ramp surface to the top of the barriers, and thus meet ADA guidelines. In this study, ramp side barriers performed sufficiently in containing the wheelchair within the ramp area in all events except during one egress incident. This incident involved a power wheelchair user who drove his/her front right wheelchair caster over the right side barrier during egress. The LATV operator assisted in placing the caster back onto the ramp and guided the wheelchair and wheelchair passenger down the ramp. With the improvements in wheelchair maneuverability and power output (especially in power wheelchairs), a raised barrier may be necessary to prevent future incidents (LaPlante, 2003). 


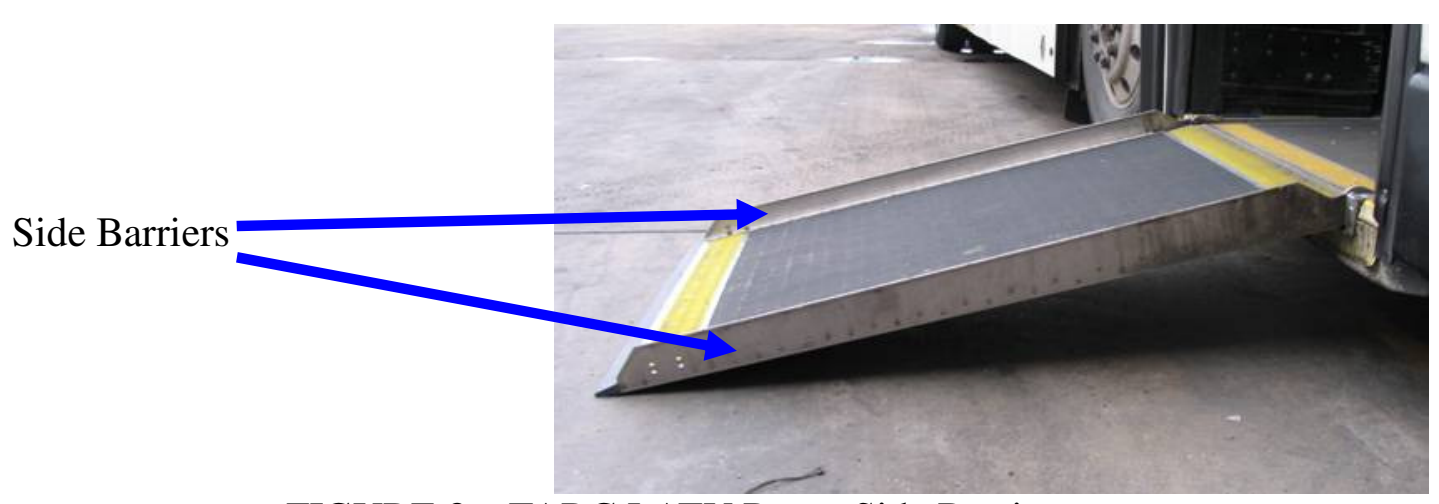

FIGURE 8 - TARC LATV Ramp Side Barriers

\section{Ramp Threshold}

The ramp threshold is located at the bottom edge of the ramp, and serves as the transition between the outer surface terrain and the ramp surface. In this study, the ramp threshold was observed as a contributing factor in 7 of 22 adverse ingress events. During the review of adverse events, observations associated with ramp threshold inadequacy included bumps, jerks, and small, sudden stops with the wheelchair wheels (both front casters and rear wheels) at the bottom of the ramp.

Ramp thresholds on TARC LATVs are beveled with a rubber wedge and meet the ADA specifications of a slope of 1:2 as shown in Figure 9. However, when the ramp is extended onto uneven terrain surface, the ramp may not be completely flush with the surface. This may be a result of uneven surface terrain or degradation of rubber material. Regardless of the underlying cause, vertical gaps between the outer terrain surface and the ramp surface may result in ramp deformation from wear and tear. In this study, the wheelchair passenger experienced minor bumps and stops when the wheelchair initiated contact with the ramp.

The ramp threshold contact with the terrain surface is related to ramp deformation which is directly influenced by ramp loads. Currently, ADA compliant ramps are 
designed for loads up to $600 \mathrm{lbs}$. Several TARC LATV ramps showed deformation when the ramp was extended, which was evident by uneven vertical gaps between the ramp threshold and the terrain surface. During video analysis, we also observed both ambulatory passengers and a wheelchair passenger occupying the ramp at the same time. With the increase in heavier wheelchairs and common occurrences of ambulatory passengers occupying the ramp simultaneously with wheelchair passengers, current ramp design specifications may not be sufficient and must be reconsidered for higher ramp loads.

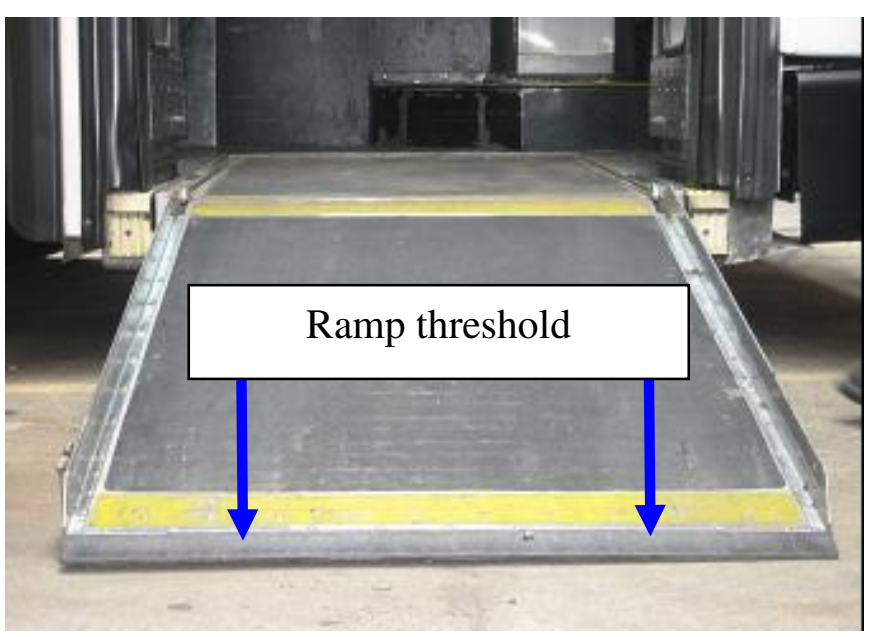

Figure 9 - TARC LATV Ramp Threshold

\section{LATV Components}

LATV components such as handrails on LATV doors, fare box, and front interior storage compartments located at the front of the LATV may obstruct the wheelchair passenger's path to fully board/exit the LATV. In this study, LATV component obstruction contributed to 9 of 22 adverse ingress events. The most common obstructions during these events involved the LATV door, fare box, and front storage compartments as 
shown in Figure 10. Integration of the fare box into the LATV front interior dashboard will eliminate the surface footprint of the fare box post which may reduce occurrences of LATV obstruction. Furthermore, reduction of front storage compartments to accommodate larger access path widths may also decrease wheelchair passenger difficulty and/or incident. Current ADA requirements only address surface widths in terms of allowable floor space for wheelchair passengers and are based on common wheelchair widths. Additional research is needed to accommodate not only large wheelchairs, but also allowable space required above the floor surface for bags and other personal items attached on the wheelchair.

Additionally, TARC LATVs are equipped with mounted interior lights that protrude into both sides of the aisle and are adjacent to the LATV door. These mounted lights protrude approximately 18 inches above the LATV floor. Although the review of video data was unable to conclusively determine whether or not these interior lights obstructed passengers observed in this study, these lights may be an additional source of LATV component obstruction. Replacing these interior light fixtures with LED floor strips may provide more room for wheelchair passengers to maneuver.

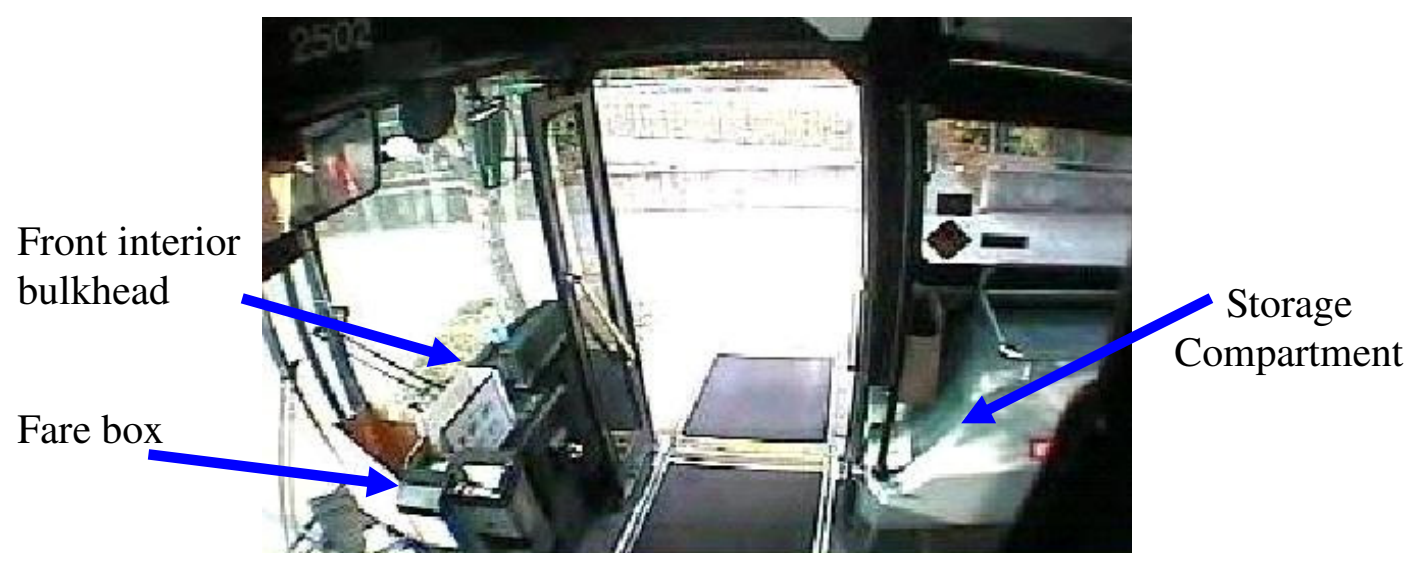

FIGURE 10 - Interior TARC LATV Components in Access Path 


\section{Human Factors: Wheelchair-Seated Passenger}

While reviewing adverse ingress/egress events, observed human factors that contributed to adverse events included: wheelchair passenger movements such as extension of the head and neck to view the items behind the wheelchair while traveling rearward; sudden jerks with the wheelchair during maneuvering; and multiple attempts in realigning the wheelchair during ingress/egress. These factors may be a result of either a physical condition of the wheelchair passenger, a level of comfort a wheelchair passenger has with maneuvering the wheelchair, or both. As shown in Table IX, there is a wide range of physical conditions among wheeled mobility device users. Specific training for wheelchair users regarding boarding and alighting LATVs may improve wheelchair passengers' skills in maneuvering both on the ramp and inside the LATV. Currently, TARC operators are provided an ADA training session and are informed on how to treat passengers with disabilities. These training sessions can be improved by providing extra guidelines such as ramp extension onto the sidewalk to better accommodate wheelchair passengers. Further investigation on techniques to improve the interaction of wheelchair passengers, wheelchairs, and accessible ramps is still needed. 
TABLE IX

LEADING CONDITIONS ASSOCIATED WITH

MOBILITY DEVICE USE, ALL AGES (KAYE, 2000)

\begin{tabular}{|lrr|}
\hline \multicolumn{1}{|c}{ Condition } & $\begin{array}{r}\text { Persons } \\
(1000 \mathrm{~s})\end{array}$ & $\begin{array}{c}\text { Proportion of } \\
\text { mobility device } \\
\text { users (\%) }\end{array}$ \\
\hline 1. Osteoarthrosis and allied disorders & 1,189 & 18.81 \\
2. Cerebrovascular disease & 442 & 6.98 \\
3. Orthopedic impairment of lower extremity & 367 & 5.8 \\
4. Orthopedic impairment of back or neck & 273 & 4.32 \\
5. Intervertebral disc disorders & 237 & 3.75 \\
6. Senility without mention of psychosis & 236 & 3.73 \\
7. Other forms of heart disease & 210 & 3.32 \\
8. Rheumatoid arthritis and other inflammatory & & 3.18 \\
polyarthropathies & 201 & 2.92 \\
9. Orthopedic impairment of hip and/or pelvis & 185 & 2.07 \\
10. Chronic injuries or late effects of injuries & 131 & 100 \\
\hline All Conditions & 6,321 & \\
\hline
\end{tabular}

\section{Operator Factors}

LATV operator factors contributing to adverse events involved ramp extension onto uneven surfaces (i.e. deploying the ramp across a curb cut and sidewalk) and ramp extension near sidewalk curbs (when ramp is deployed onto street). Figure 11 shows an example of the ramp being halfway extended onto the street and the other half onto curb 
cut. In this study, ramp deployment onto uneven terrain and/or inadequate clearance beyond the ramp contributed in 5 of 22 adverse ingress events (see Appendix II). These factors may contribute to frustration for wheelchair passengers who have to perform multiple back and forth maneuvers to overcome the uneven terrain or limited clearance. Consequently, these factors may also increase ingress time, which may delay the fixedroute schedule to which LATV operators must adhere to for other passengers who rely on their services. There were no ramp extension issues that contributed to adverse egress events. Additional LATV operator training is recommended to ensure the ramp is deployed with sufficient clearance for wheelchair passenger ingress/egress. In addition, public obstructions such as bike racks, LATV stop shelters, fire hydrants, and trashcans should be avoided.

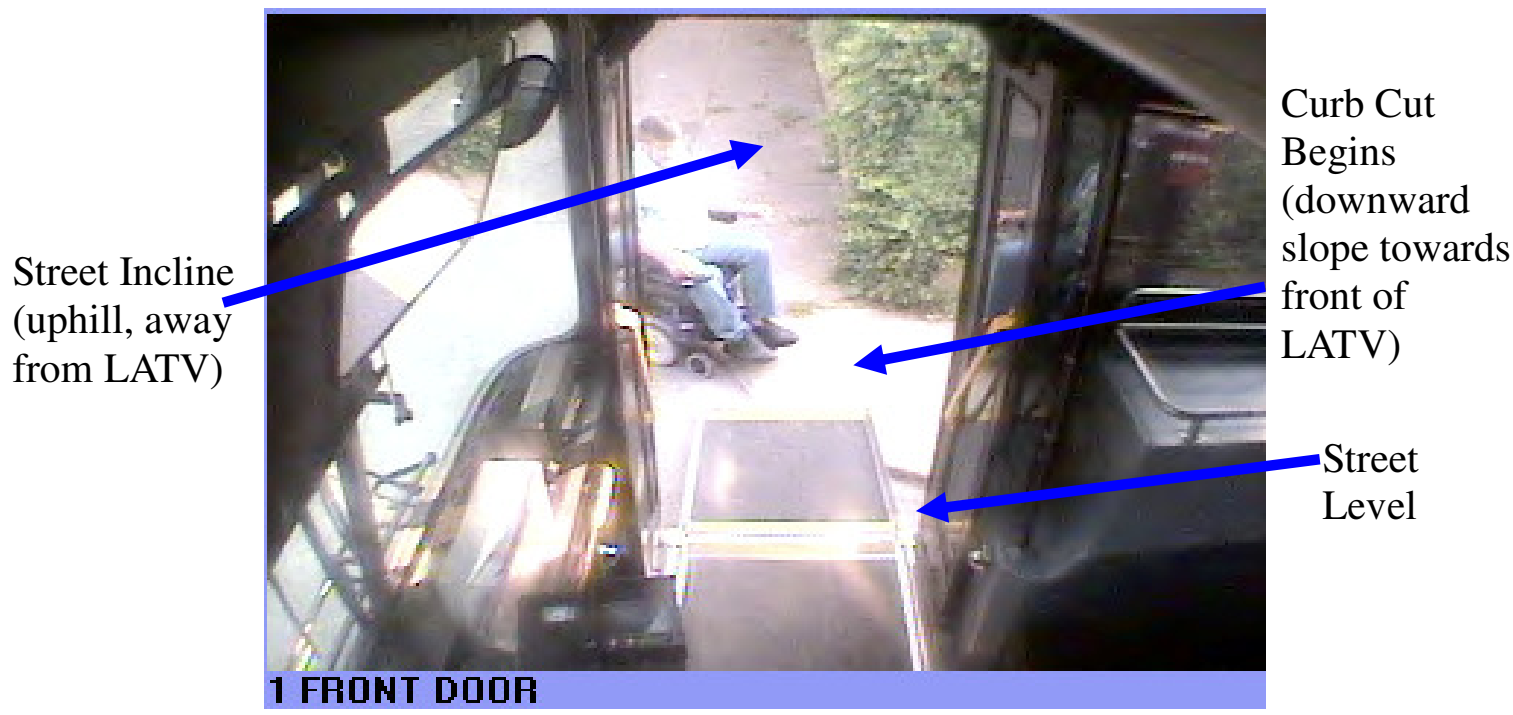

FIGURE 11 - Example of ramp deployment onto uneven surfaces 


\section{$\underline{\text { C. Perception of Time in Fixed-Route Schedules }}$}

Time is an important factor to transit service providers since fixed-route passengers rely on public transportation to get them to work, school, appointments, and other daily activities. Thus, there is a pressure for LATV operators to complete their route in a timely manner. Buning et al. (2007) conducted a web-based survey to identify accessibility barriers to wheelchair users during the transport experience. The survey participants were wheelchair users who were fixed-route riders and used a wheelchair as their primary means of mobility. Of the 283 wheelchair users who participated in the survey, approximately $40 \%$ of the participants reported that bus operator attitude varied by the driver and the time of day. LATV operator attitudes were more negative during peak usage hours. Moreover, $17.6 \%$ of the survey population perceived that the bus driver had "negative" and "uninformed attitudes" towards them. However, 18\% reported that the bus driver had a positive and helpful attitude when the bus was running on schedule (Buning, 2007).

In this study, adverse events had longer completion times compared to successful events for both ingress and egress. According to Table X, adverse ingress events took an average of 10 seconds longer than successful ingress events. Similarly, adverse egress events and successful egress events had an average time difference of 14 seconds. Although there is a need to look at each event to see what combination of factors may have contributed to the prolonged time, adverse events in general cause delays in fixedroute schedules. In these events, operator and human factors were observed as primary causes of delays (see Appendix II and III). These delays may result in neglect of other 
activities involved in a wheelchair boarding, such as proper securement and restraints, in addition to frustration and pressures associated with time constraints for LATV operators, wheelchair-seated passengers, and ambulatory passengers. Improved operator training and wheelchair-seated passenger procedures will help reduce the time to complete ingress/egress. Further research is needed to investigate how much the ramp slope impacts the time wheelchair-seated passengers take to ascend and descend the ramp. Additional research is also needed to observe if time pressures affect other wheelchairrelated boarding activities, especially securement and restraint.

TABLE X

COMPLETION TIMES OF INGRESS AND EGRESS EVENTS

\begin{tabular}{|c|c|c|c|}
\hline \multicolumn{4}{|c|}{ INGRESS EVENTS (sec) } \\
\hline \multicolumn{2}{|c|}{ Successful Events $(\mathrm{N}=86)$} & \multicolumn{2}{|c|}{ Adverse Events $(\mathrm{N}=22)$} \\
\hline Avg. & SD & Avg. & SD \\
\hline 7 & 11 & 17 & 15 \\
\hline \multicolumn{4}{|c|}{ EGRESS EVENTS (sec) } \\
\hline \multicolumn{2}{|c|}{ Successful Events $(\mathrm{N}=104)$} & \multicolumn{2}{|c|}{ Adverse Events $(\mathrm{N}=4)$} \\
\hline Avg. & SD & Avg. & SD \\
\hline 5 & 3 & 19 & 13 \\
\hline
\end{tabular}




\section{Limitations}

There are a few limitations to the study that should be considered when interpreting this data. First, there is limited variation in geographical location and climate. The Louisville metropolitan area, to which TARC provides transportation services, has fairly even terrain and does not have steep inclines such as large hills. Thus, these results cannot be generalized to other locations. Also, the majority of the events occurred during sunny weather conditions. There was very little or no data to describe events occurring during snowy and rainy weather.

Second, the sample population observed in this data may include wheelchair passengers who appeared in more than one boarding event. TARC provides service to many fixed-route wheelchair passengers, and throughout the 10-month period study it is

probable to have reviewed the same wheelchair passenger more than once. This may have influenced the data presented since there may have been multiple boardings/alightings of the same wheelchair passenger with more maneuvering skills or similarly, multiple boardings/alightings of a wheelchair passenger with limited control ability.

There are also limitations associated with the camera position and overall video recording system. The camera view used to view ingress/egress activity was focused on the ramp and mounted above the LATV operator's seat. The camera distance, combined with the video capture rate per camera (6 frames per second), limited the level of detail observed during each event. Ramp threshold details, for example, could not be determined since the camera view did not capture whether or not the threshold was completely level with the outer terrain surface. Also, it was not possible to quantify the 
extent of LATV kneeling from the video analysis. Results suggest that ramp slope is an important factor affecting usability due to angle of incline; however, LATV height at which the ramp was deployed could not be measured.

Finally, there are limitations due to the retrospective nature of this study. Analysis was limited to the observations generated from video which did not allow further investigation of events involving passenger difficulty and incidents. Details such as whether or not the wheelchair passenger assistance was required could not be obtained.

\section{E. Recommendations for Future Ramp Safety Guidelines}

\section{Design Opportunities}

From the review of wheelchair ingress/egress adverse events, findings show a need for design opportunities regarding the ramp and the LATV. First, the ramps should be tested for loads greater than 600 pounds. In this study, approximately $73 \%$ of the wheelchairs used during the ingress/egress events were powered. Power wheelchairs can range from 200 to 350 pounds and may reach upper static design limits when the weight of the wheelchair user is considered. Additional bags and personal items attached onto the wheelchair also contribute to the overall weight to the wheelchair and wheelchair system. Furthermore, in this study we observed both ambulatory and wheelchair passengers occupying the ramp at the same time. A greater design load may increase the life of the ramp and will have a higher resistance to deflection which appeared to have contributed to adverse events in relation to the ramp threshold. Ramp design loads should also 
accommodate heavier wheelchair devices, given the increase in population of bariatric wheelchair users.

Ramp width for LATVs should be increased to accommodate the "over-sized" wheelchairs that were not only observed in this study, but also in the increasing trend for larger wheelchairs in the market industry (RERC UD, 2004). Also, the width of the LATV door and entry should be increased to accommodate larger wheelchairs and objects that may protrude on the sides of the wheelchair such as arms, hands, and personal bags. Thus, in addition to ramp changes, LATV door width, placement of protruding interior entry lighting, and entry aisle width changes should also be considered.

Lastly, the height of the side barriers in relation to power wheelchair and scooter propulsion should be further investigated. The power required to overcome obstacles such as side barriers is proportional to weight of the wheelchair, wheelchair user, and personal items. Based on the only incident that occurred in this study, the side barriers failed to contain the wheelchair within the ramp surface area. An increase in the height of the side barriers may have prevented the wheelchair and/or any wheelchair components from traversing over the ramp side barrier.

\section{Training Opportunities}

There should be additional training to enhance successful ingress/egress events for LATV operators. Based on review of ingress/egress events, the following are training topics that may help reduce adverse ingress/egress events:

1) Kneel the LATV fully to ensure the height of the LATV is as close to the curb 
height as possible. This reduces the slope of the ramp when it is deployed.

2) Extension of the ramp should be at the sidewalk level at all times unless a sidewalk is not present. This reduces the ramp angle of ascent/descent for the wheelchair passenger and may prevent passenger difficulty.

3) The surface terrain beyond where the ramp is extended should be clear and have little or no obstructions to allow the wheelchair passenger enough clearance to align his/her wheelchair with the ramp. Obstructions such as fire hydrants, street trashcans and bicycle racks should be avoided.

4) Extension of the ramp should be on a leveled surface. Ramp extensions onto uneven surfaces such as curb cuts will result in a vertical gap between the ramp threshold and the outer terrain and may lead to an adverse event.

5) Educate drivers on the advantages and disadvantages of rear-facing versus forward-facing orientation when ascending the ramp and factors that may contribute to difficulties.

6) Permission should be asked prior to assisting wheelchair passengers. This prevents the assumption of whether or not assistance is required and also respects the independence of wheelchair passengers. 


\section{CONCLUSIONS}

The purpose of this study was to review and characterize wheelchair ingress and egress activities occurring on LATVs and to examine factors that may contribute to adverse events. In this study, 26 of $216(12 \%)$ total ingress/egress events resulted in a passenger difficulty or an incident. Factors relating to ramp slope, which is influenced by ramp extension level, appeared to contribute to adverse events, primarily during ingress due to increased ramp angle of incline. Furthermore, a rear-facing orientation may also present a challenge to wheelchair passengers during ingress due to limited visibility while maneuvering. Through an evaluation of adverse events with respect to ADA ramp guidelines, ramp width and ramp threshold appeared to play a role in passenger difficulties and incidents. Other factors, such as maneuvering abilities of the wheelchair passenger and LATV component obstruction may also contribute to adverse events. Recommendations were made to improve LATV ramp safety, accessibility and usability, and to help transit providers enhance LATV operator procedures. 


\section{REFERENCES}

Americans with Disabilities Act (ADA) Accessibility Guidelines for Transportation Vehicles, Architectural and transportation Barriers Compliance Board (ATBCB), 36 CFR Part 1192, Federal Register, Vol. 56, No. 173. September 1991

Americans with Disabilities Act (ADA) Accessibility Guidelines for Transportation Vehicles, Architectural and transportation Barriers Compliance Board (ATBCB), 49 CFR Part 38. October 2001

Buning ME, Getchell CA, Bertocci GE, Fitzgerald SG (2007). Riding a bus while seated in a wheelchair: A pilot study of attitudes and behavior regarding safety practices. Assistive Technology, 19(4), p. 166-79.

Fatal Accident Reporting System. Retrieved from http://www-nrd.nhtsa.dot.gov

Federal Transit Administration (FTA) Guideline Specifications for Transit Vehicle Ramps. September 1992

Fitzgerald S, Songer T, Rotko K, Karg P (2007). Motor Vehicle Transportation Use and Related Adverse Events Among Persons Who Use Wheelchairs. Assistive technology 19.4, 180-7.

Frost KL, Bertocci G. Wheelchair Rider Incidents on Public Transit Buses: A 4-Year Retrospective Review of Metropolitan Transit Agency Records. Rehabilitation Engineering Society of North America, Annual Conference, Phoenix AZ, June 2007.

GE MobileView III Product Manual. GE Security, Inc. Bradenton, FL. Product manual online www.gesecurity.com/portal/GESDownload?ID=724\&DID=12661\&documenttype=Produ ct\%20Brochure

Kaye, H.S., Kang, T. and LaPlante, M.P. (2000). Mobility Device Use in the United States. Disability Statistics Report, (14). Washington, D.C.: U.S. Department of Education, National Institute on Disability and Rehabilitation Research.

Kirby RL, Sampson M, Thoren F, MacLeod DA (1995). Wheelchair Stability: Effect of Body Position. Journal of Rehabilitation Research and Development, 32(4), p. 367-372.

LaPlante M. Demographics of Wheeled Mobility Device Users, Space Requirements for Wheeled Mobility Device Users Workshop Proceedings. Center for Inclusive Design and Environmental Access. University of Buffalo, State University of New York, Buffalo, New York. October 2003. 
National Council on Disability (NCD) The Current State of Transportation for People with Disabilities in the United States. June 2005

National Highway Traffic Safety Administration (NHTSA) National Center for Statistics and Analysis. Wheelchair Users Injuries and Deaths Associated with Motor Vehicle Related Incidents. Research Note. September 1997. Retrieved from, wwwnrd.nhtsa.dot.gov/Pubs/97.850.pdf

Rakestraw R, Transit Authority of River City, Louisville, KY, Personal Communication

Richardson, H.A. (1991). Wheelchair occupants injury in motor vehicle-related accidents. Washington, D.C.: National Center for Statistics and Analysis Mathematical Analysis Division, U.S. Department of Transportation.

Rotko K, Songer T, Fitzgerald S, Karg P. Injury to Wheelchair Users as a Result of Loading and Unloading from a Motor Vehicle. Rehabilitation Engineering Society of North America, Annual Conference, Atlanta GA, June 2005.

Shaw G (2000). Wheelchair rider risk in motor vehicles; a technical note. J Rehab Res Develop, 37(1), p. 89-100.

Songer T, Fitzgerald S, Rotko K, (2004). The injury risk to wheelchair occupants using motor vehicle transportation. Annual Proc Assoc Adv Automotive Med, 48 p. 115-29.

Steinfeld E, Maisel J, Feathers D (2005). Standards and Anthropometry for Wheeled Mobility. Center for Inclusive Design and Environmental Access (IDEA). Report prepared for U.S. Access Board, Washington, DC. Retrieved from http://www.ap.buffalo.edu/idea/Anthro/FinalAccessReport.htm

U.S. Census Bureau. Americans with Disabilities in 2002. Population Profile Report. 2002. Retrieved from, www.census.gov/population/pop-profile/dynamic/Disability.pdf.

U.S. Consumer Product Safety Commision National Electronic Injury Surveillance System Database. Retrieved from http://www.cpsc.gov/LIBRARY/neiss.html 


\section{APPENDIX I.}

WHEELCHAIR MONITORING DATABASE (INGRESS/EGRESS)

\section{Wheelchair Transportation Monitoring Database}

Tracking No.

Video File name

Date of Event

Start Time of Event

def: When the front wheels of the WMD touch bus ramp

\section{General Information}
a. WMD type
b. Gender $1=$ male, $2=$ female

$1=$ manual, $2=$ power WC, $3=$ scooter, $4=$ other

c. Bags ATTACHED to WMD? $1=y e s, 2=$ no, 3 =cannot determine

i) If yes, specify where attached

Bag $1 \quad$ Bag 2 (location relative to WMD occupant)

ii) Total bags present

$0=n / a, 1=$ behind WMD, $2=$ left side, $3=$ right side, $4=$ scooter tiller

d. Bags CARRIED by WMD occupant? (includes fanny packs/other object) $0=n / a, 1=1$ bag, $2=2+$ bags

i) If yes, specify location

$1=y e s, 2=$ no, $3=$ cannot determine

e. Assistive/Medical device present?

i) If yes, please explain

$0=n / a, 1=0 c c u p a n t ' s$ lap/seat area, $2=a r m s / h a n d s, 3=$ footrest

Driving Conditions

g. Was the WMD user/passenger seated in WMD the whole time on bus?

$0=n / a, 1=0 x y g e n$ tank, $2=A \cup G / C O M$ device, $3=$ service dog, $4=0$ ther

h. Comments

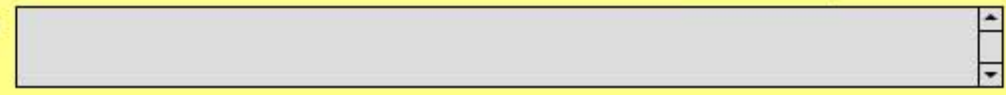

II. Ingress: boarding

a. Start Time def: When the front wheels of the WMD touch bus ramp

b. Lowering (kneeling) of bus

c. Ramp extended? $1=y e s, 2=$ no, 3=cannot determine

i) If yes, was ramp extended onto the street, sidewalk, or other?

d. Outer terrain surface

$1=s m o o t h$ concrete, $2=$ uneven concrete/pavement, $3=$ dirt/grass, $4=$ gravel, $5=$ smooth pavernent, $6=$ cannot determine

e. WMD entrance orientation on ramp

$0=n / a, 1=$ backward, $2=$ forward, $3=$ WMD

Rrmises passenger pushed WMD up ramp 


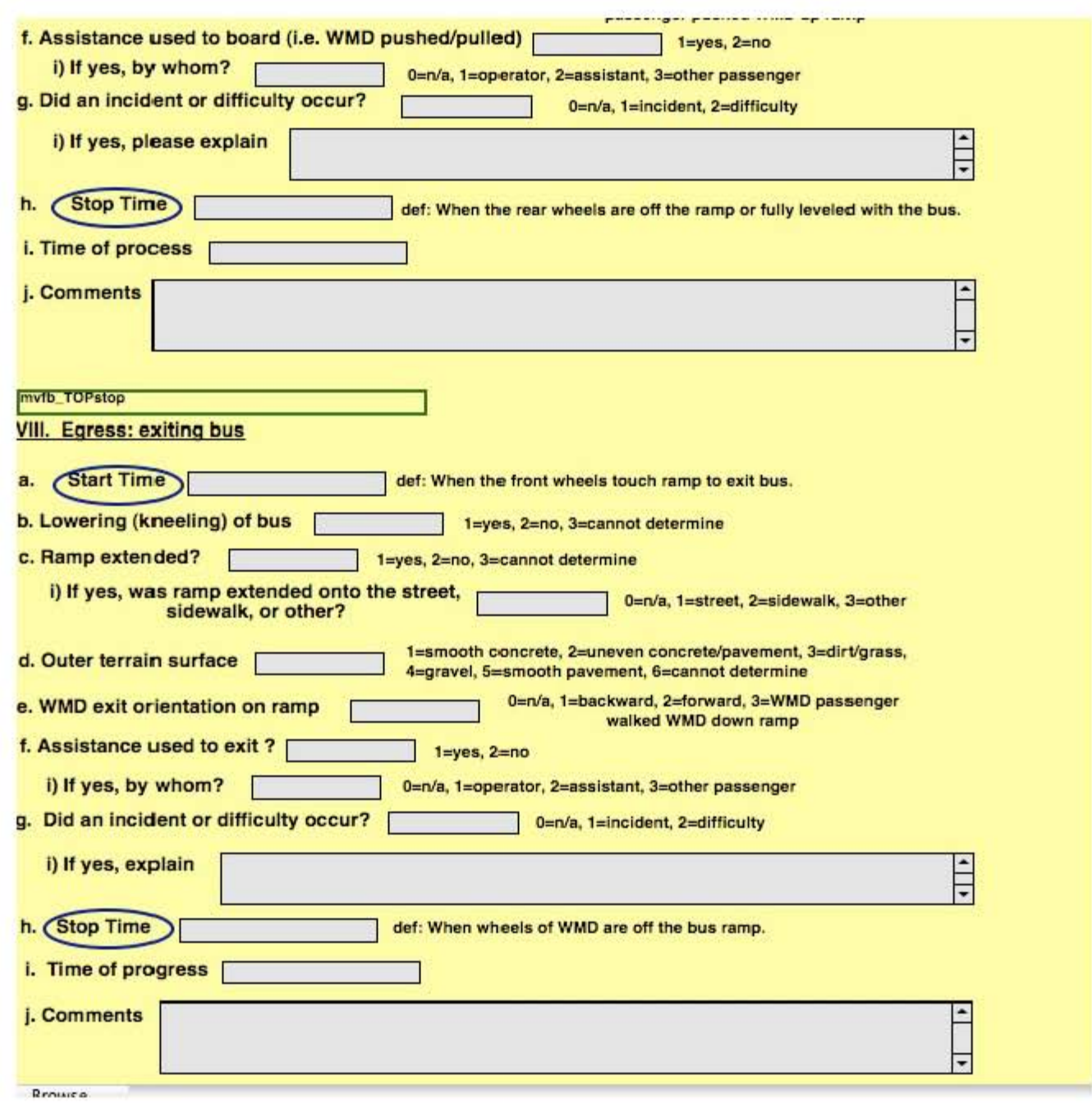


APPENDIX II.

ADVERSE INGRESS EVENT EVALUATION OF CURRENT LEGISLATIVE

GUIDELINES

\begin{tabular}{|c|c|c|c|c|c|}
\hline $\begin{array}{c}\text { Track } \\
\text { No }\end{array}$ & Comment/Narrative & & Adequate & $\begin{array}{l}\text { Not } \\
\text { Adequate }\end{array}$ & $\begin{array}{l}\text { Cannot } \\
\text { Determine }\end{array}$ \\
\hline \multirow{7}{*}{1} & \multirow{7}{*}{$\begin{array}{l}\text { WC Type: Power WC. } \\
\text { Ramp extension: Street. } \\
\text { LATV operator } \\
\text { deployed the ramp half } \\
\text { onto curb cut and other } \\
\text { half onto pavement } \\
\text { (street) surface. } \\
\text { Wheelchair passenger } \\
\text { could not successfully } \\
\text { traverse length of ramp } \\
\text { and had to pull himself } \\
\text { up the ramp by grabbing } \\
\text { the LATV door handle. }\end{array}$} & Width & $\mathrm{x}$ & & \\
\hline & & $\begin{array}{l}\text { Ramp } \\
\text { Threshold }\end{array}$ & $\mathrm{x}$ & & \\
\hline & & $\begin{array}{l}\text { Side } \\
\text { Barriers }\end{array}$ & $\mathrm{x}$ & & \\
\hline & & Slope & & $\mathrm{X}$ & \\
\hline & & $\begin{array}{l}\text { LATV } \\
\text { Component }\end{array}$ & $\mathrm{x}$ & & \\
\hline & & $\begin{array}{l}\text { Human } \\
\text { Passenger }\end{array}$ & $\mathrm{x}$ & & \\
\hline & & Operator & & $\mathrm{x}$ & \\
\hline \multirow{7}{*}{3} & \multirow{7}{*}{$\begin{array}{l}\text { WC Type: Power WC. } \\
\text { Ramp extension: } \\
\text { Sidewalk. Front casters } \\
\text { and rear wheels were } \\
\text { stuck (at different times) } \\
\text { on the ramp threshold. } \\
\text { At the middle of the } \\
\text { ramp, wheelchair } \\
\text { passenger appeared to } \\
\text { experience difficulty in } \\
\text { ascending the ramp, and } \\
\text { his wheelchair waivered } \\
\text { to his right side then left } \\
\text { side without ascending } \\
\text { any further. The LATV } \\
\text { operator asked if } \\
\text { assistance was needed. } \\
\text { Another passenger }\end{array}$} & Width & $\mathrm{X}$ & & \\
\hline & & $\begin{array}{l}\text { Ramp } \\
\text { Threshold }\end{array}$ & & $\mathrm{x}$ & \\
\hline & & $\begin{array}{l}\text { Side } \\
\text { Barriers }\end{array}$ & $\mathrm{x}$ & & \\
\hline & & Slope & & $\mathrm{x}$ & \\
\hline & & $\begin{array}{l}\text { LATV } \\
\text { Component }\end{array}$ & $\mathrm{x}$ & & \\
\hline & & $\begin{array}{l}\text { Wheelchair- } \\
\text { seated } \\
\text { Passenger }\end{array}$ & & $\mathrm{x}$ & \\
\hline & & Operator & $\mathrm{X}$ & & \\
\hline
\end{tabular}




\begin{tabular}{|c|c|c|c|c|}
\hline & $\begin{array}{l}\text { offered assistance to the } \\
\text { LATV operator. This } \\
\text { passenger assisted by } \\
\text { grabbing the aug com } \\
\text { device/lap tray area to } \\
\text { pull up } \\
\text { wheelchair/wheelchair } \\
\text { passenger. Wheelchair } \\
\text { passenger had limited } \\
\text { abilities in head rotation. }\end{array}$ & & & \\
\hline \multirow{7}{*}{7} & \multirow{7}{*}{$\begin{array}{l}\text { WC Type: Power WC. } \\
\text { Ramp extension: } \\
\text { Sidewalk. The } \\
\text { wheelchair passenger } \\
\text { bumped the right side } \\
\text { barrier at the bottom of } \\
\text { the ramp while } \\
\text { ascending the ramp in a } \\
\text { rear-facing manner. } \\
\text { After bump, the } \\
\text { wheelchair passenger } \\
\text { moved her wheelchair } \\
\text { forward and back } 2-3 \\
\text { times to align the } \\
\text { wheelchair and continue } \\
\text { ascending the ramp. The } \\
\text { LATV operator } \\
\text { provided verbal } \\
\text { guidance to the } \\
\text { wheelchair passenger to } \\
\text { assure that her } \\
\text { wheelchair was properly } \\
\text { aligned and there were } \\
\text { no obstructions in her } \\
\text { path. }\end{array}$} & Width & $\mathrm{x}$ & \\
\hline & & $\begin{array}{l}\text { Ramp } \\
\text { Threshold }\end{array}$ & $\mathrm{x}$ & \\
\hline & & $\begin{array}{l}\text { Side } \\
\text { Barriers }\end{array}$ & $\mathrm{X}$ & \\
\hline & & Slope & $\mathrm{X}$ & \\
\hline & & $\begin{array}{l}\text { LATV } \\
\text { Component }\end{array}$ & $\mathrm{x}$ & \\
\hline & & $\begin{array}{l}\text { Wheelchair- } \\
\text { seated } \\
\text { Passenger }\end{array}$ & & $\mathrm{X}$ \\
\hline & & Operator & $\mathrm{X}$ & \\
\hline \multirow[t]{4}{*}{16} & \multirow{4}{*}{$\begin{array}{l}\text { WC Type: Power WC. } \\
\text { Ramp extension: } \\
\text { Sidewalk. Wheelchair } \\
\text { passenger experienced } \\
\text { difficulty at the top of } \\
\text { the ramp/inside LATV } \\
\text { when he bumped the } \\
\text { fare box while boarding } \\
\text { the LATV in a rear- } \\
\text { facing manner. }\end{array}$} & Width & $\mathrm{X}$ & \\
\hline & & $\begin{array}{l}\text { Ramp } \\
\text { Threshold }\end{array}$ & $\mathrm{X}$ & \\
\hline & & $\begin{array}{l}\text { Side } \\
\text { Barriers }\end{array}$ & $\mathrm{X}$ & \\
\hline & & Slope & $\mathrm{X}$ & \\
\hline
\end{tabular}




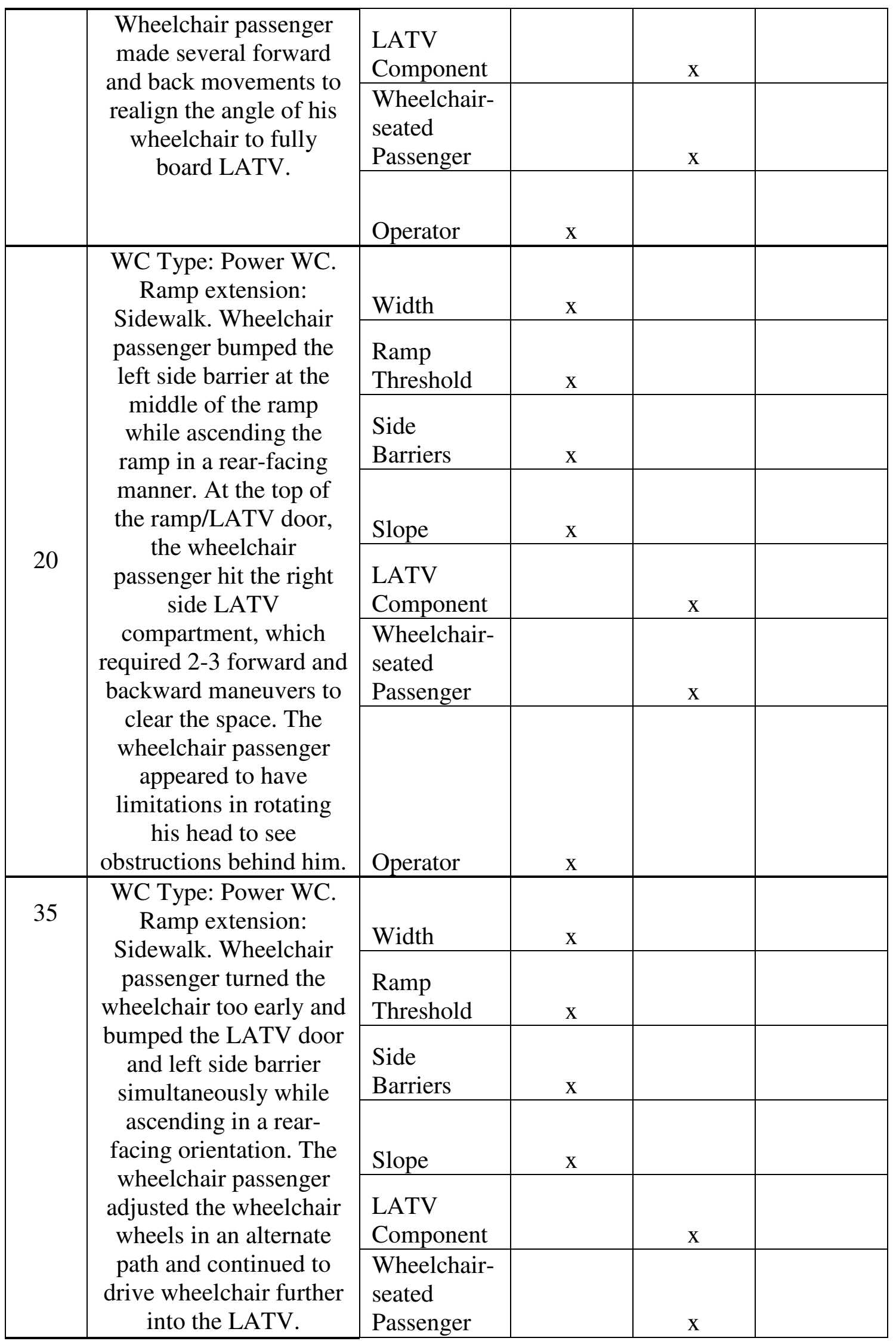




\begin{tabular}{|c|c|c|c|c|}
\hline & \multirow{8}{*}{$\begin{array}{l}\text { WC Type: Manual WC. } \\
\text { Ramp extension: } \\
\text { Sidewalk. Difficulty 1) } \\
\text { Rear left wheel of a } \\
\text { bariatric wheelchair hit } \\
\text { the left side barrier at the } \\
\text { bottom of the ramp } \\
\text { while using in a rear- } \\
\text { facing orientation. } \\
\text { Wheelchair passenger } \\
\text { realigned her wheelchair } \\
\text { by moving forward and } \\
\text { then back } 2 \text { times before } \\
\text { going over the ramp } \\
\text { threshold. Difficulty } 2 \text { ) } \\
\text { At the middle of the } \\
\text { ramp, wheelchair } \\
\text { passenger appeared to } \\
\text { have a decrease in } \\
\text { push/pull strength of the } \\
\text { manual wheelchair } \\
\text { while trying to ascend } \\
\text { the ramp due to a } \\
\text { decrease in momentum. } \\
\text { The LATV operator } \\
\text { provided assistance by } \\
\text { pulling the push/pull } \\
\text { handles of the } \\
\text { wheelchair up the ramp } \\
\text { and into the LATV. } \\
\text { During this process, the } \\
\text { wheelchair/wheelchair } \\
\text { passenger was } \\
\text { unintentionally bumped } \\
\text { into the front, right } \\
\text { LATV storage } \\
\text { compartment. }\end{array}$} & Operator & $\mathrm{x}$ & \\
\hline \multirow[b]{7}{*}{40} & & Width & & $\mathrm{X}$ \\
\hline & & $\begin{array}{l}\text { Ramp } \\
\text { Threshold }\end{array}$ & & $\mathrm{X}$ \\
\hline & & $\begin{array}{l}\text { Side } \\
\text { Barriers }\end{array}$ & $\mathrm{x}$ & \\
\hline & & Slope & & $\mathrm{X}$ \\
\hline & & $\begin{array}{l}\text { LATV } \\
\text { Component }\end{array}$ & & $\mathrm{X}$ \\
\hline & & $\begin{array}{l}\text { Wheelchair- } \\
\text { seated } \\
\text { Passenger }\end{array}$ & & $\mathrm{X}$ \\
\hline & & Operator & $\mathrm{X}$ & \\
\hline \multirow[t]{2}{*}{42} & \multirow{2}{*}{$\begin{array}{l}\text { WC Type: Manual WC. } \\
\text { Ramp extension: } \\
\text { Sidewalk. Rear wheels } \\
\text { of the over-sized } \\
\text { wheelchair (perhaps }\end{array}$} & Width & & $\mathrm{X}$ \\
\hline & & $\begin{array}{l}\text { Ramp } \\
\text { Threshold }\end{array}$ & & $\mathrm{X}$ \\
\hline
\end{tabular}




\begin{tabular}{|c|c|c|c|c|c|}
\hline & \multirow{5}{*}{$\begin{array}{c}\text { bariatric WC) were } \\
\text { stuck on the ramp } \\
\text { threshold while } \\
\text { wheelchair passenger } \\
\text { was using a rear-facing } \\
\text { boarding orientation. } \\
\text { The } \\
\text { wheelchair/passenger } \\
\text { was successful on the } \\
\text { second attempt in going } \\
\text { over ramp threshold. } \\
\text { Also, wheelchair } \\
\text { passenger hit the LATV } \\
\text { front door while trying } \\
\text { to position wheelchair to } \\
\text { pass through the main } \\
\text { aisle. }\end{array}$} & $\begin{array}{l}\text { Side } \\
\text { Barriers }\end{array}$ & $\mathrm{x}$ & & \\
\hline & & Slope & & $\mathrm{x}$ & \\
\hline & & $\begin{array}{l}\text { LATV } \\
\text { Component }\end{array}$ & & $\mathrm{x}$ & \\
\hline & & $\begin{array}{l}\text { Wheelchair- } \\
\text { seated } \\
\text { Passenger }\end{array}$ & & $\mathrm{X}$ & \\
\hline & & Operator & $\mathrm{X}$ & & \\
\hline \multirow{7}{*}{43} & \multirow{7}{*}{$\begin{array}{l}\text { WC Type: Manual WC. } \\
\text { Ramp extension: } \\
\text { Sidewalk. Rear wheels } \\
\text { (of a large wheelchair) } \\
\text { got stuck on the ramp } \\
\text { threshold. While } \\
\text { wheelchair passenger } \\
\text { was about to make } \\
\text { another attempt to go } \\
\text { over threshold, the } \\
\text { LATV operator } \\
\text { provided assistance } \\
\text { (without asking } \\
\text { wheelchair passenger) } \\
\text { by pulling wheelchair up } \\
\text { the ramp by its push/pull } \\
\text { handles. }\end{array}$} & Width & & $\mathrm{x}$ & \\
\hline & & $\begin{array}{l}\text { Ramp } \\
\text { Threshold }\end{array}$ & & $\mathrm{X}$ & \\
\hline & & $\begin{array}{l}\text { Side } \\
\text { Barriers }\end{array}$ & $\mathrm{x}$ & & \\
\hline & & Slope & & & $X$ \\
\hline & & $\begin{array}{l}\text { LATV } \\
\text { Component }\end{array}$ & $\mathrm{X}$ & & \\
\hline & & $\begin{array}{l}\text { Wheelchair- } \\
\text { seated } \\
\text { Passenger }\end{array}$ & & $\mathrm{x}$ & \\
\hline & & Operator & $\mathrm{X}$ & & \\
\hline \multirow[t]{4}{*}{54} & \multirow{4}{*}{$\begin{array}{l}\text { WC Type: Power WC. } \\
\text { Ramp extension: Street. } \\
\text { Wheelchair got stuck at } \\
\text { the top of the ramp when } \\
\text { it bumped the left } \\
\text { side/LATV door while } \\
\text { wheelchair passenger } \\
\text { was using a rear-facing } \\
\text { boarding orientation. } \\
\text { Wheelchair passenger }\end{array}$} & Width & $\mathrm{x}$ & & \\
\hline & & $\begin{array}{l}\text { Ramp } \\
\text { Threshold }\end{array}$ & $\mathrm{x}$ & & \\
\hline & & $\begin{array}{l}\text { Side } \\
\text { Barriers }\end{array}$ & $\mathrm{X}$ & & \\
\hline & & Slope & $\mathrm{X}$ & & \\
\hline
\end{tabular}




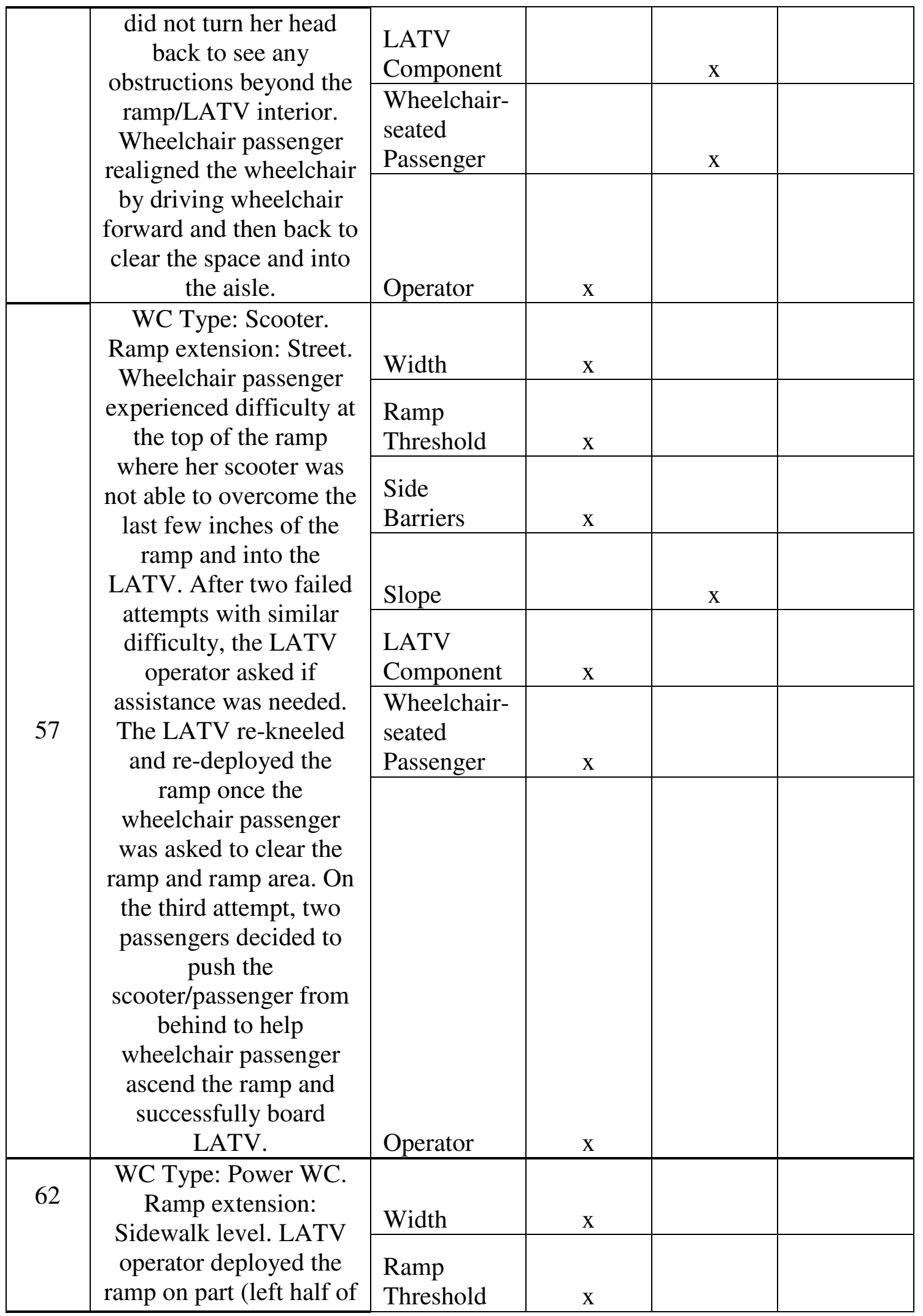




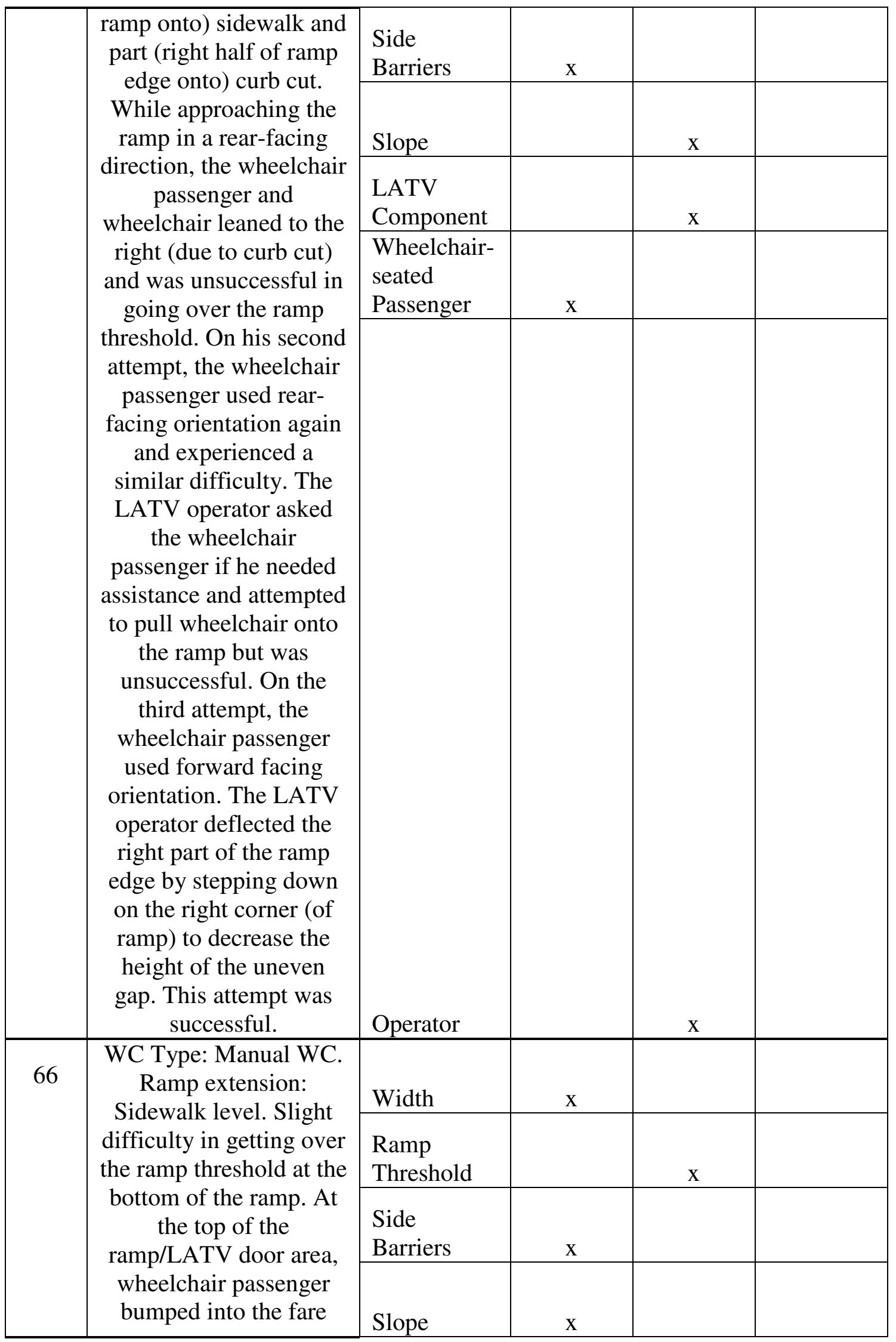




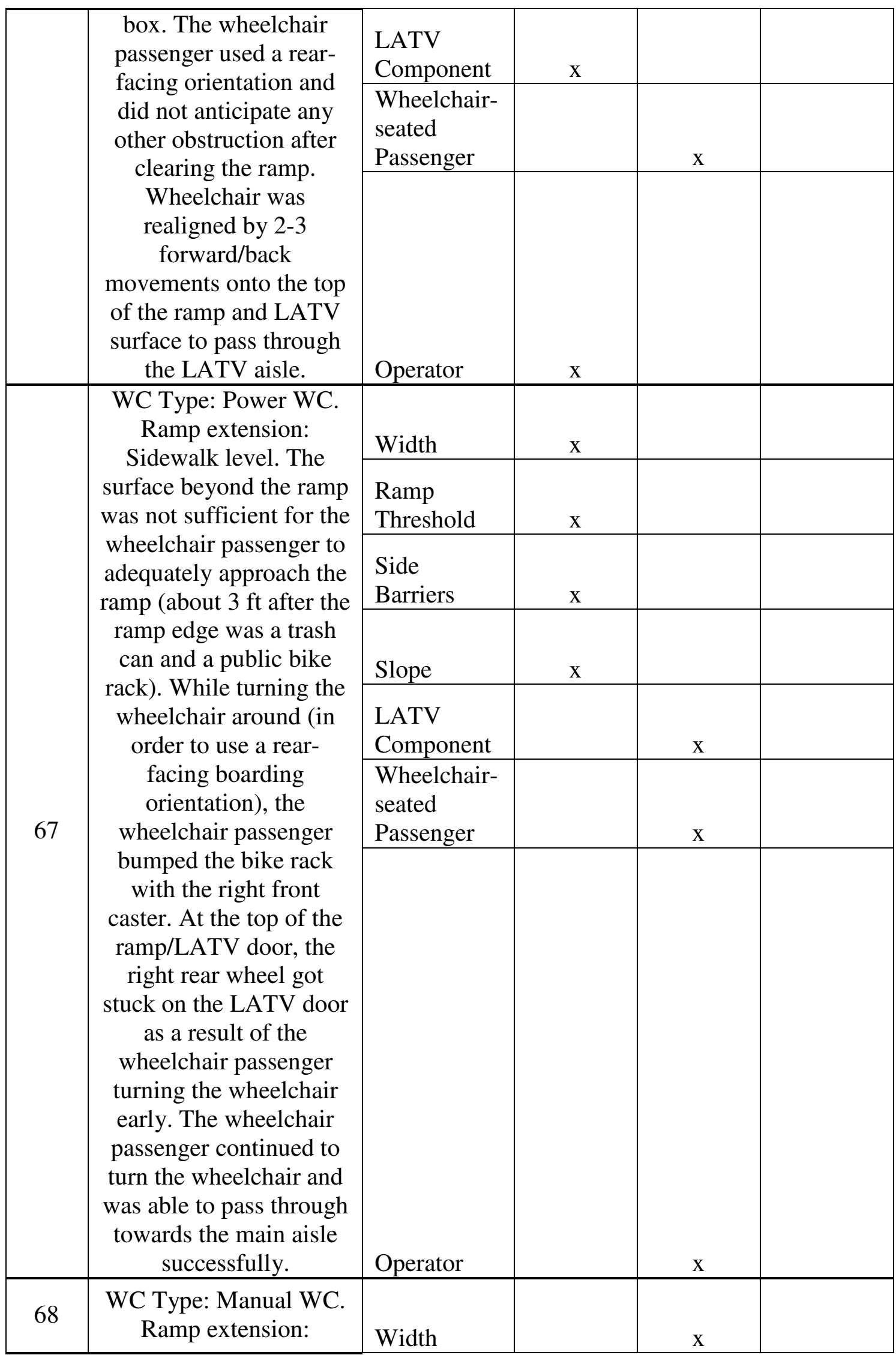




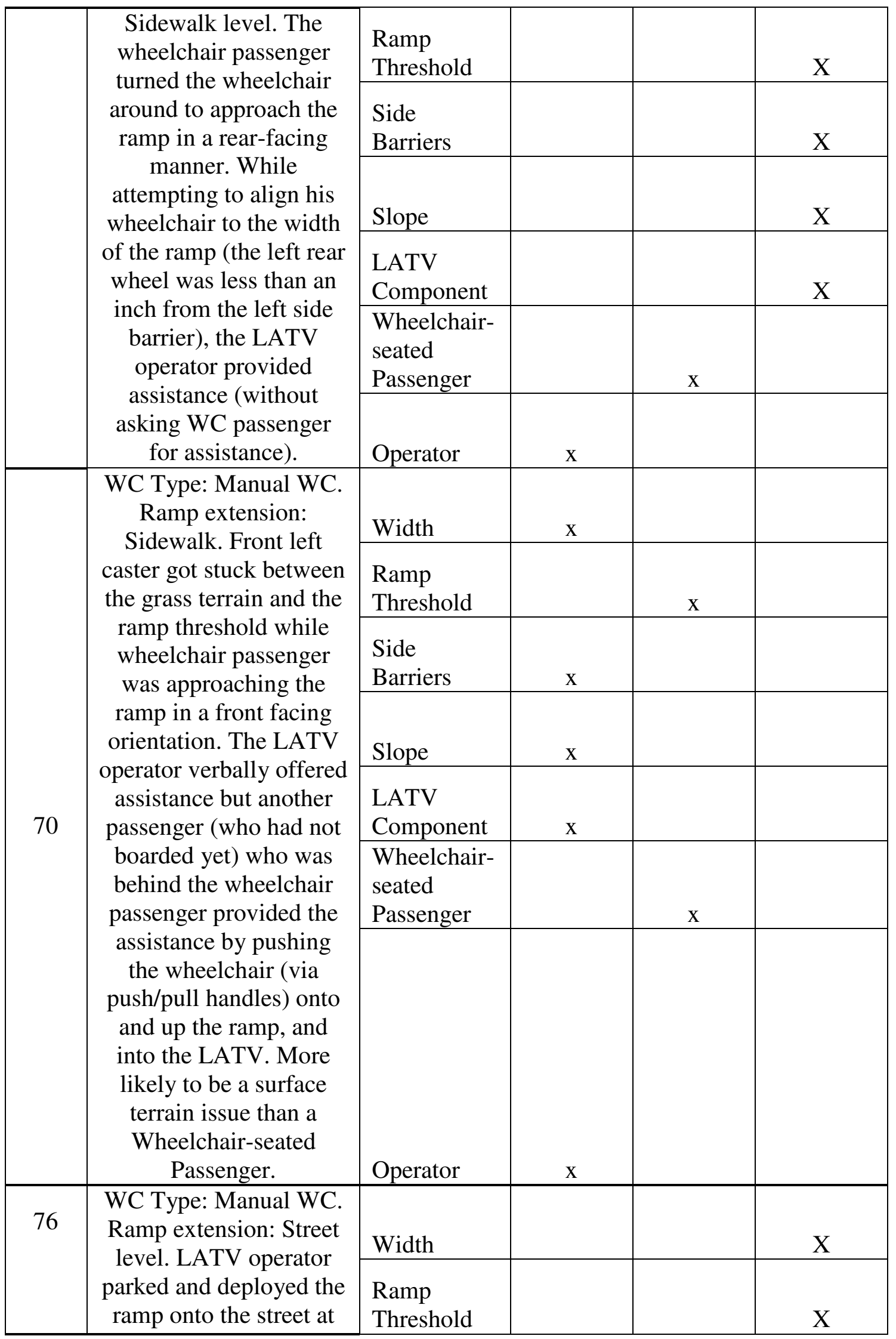




\begin{tabular}{|c|c|c|c|c|c|}
\hline & \multirow{5}{*}{$\begin{array}{l}\text { an angle (not parallel } \\
\text { with the curb). } \\
\text { Wheelchair passenger } \\
\text { was not given enough } \\
\text { clearance to board the } \\
\text { LATV since the curb at } \\
\text { its bottleneck (right edge } \\
\text { of the ramp and the } \\
\text { curb) provided less than } \\
2 \text { ft of space, which does } \\
\text { not provide space for } \\
\text { any common } \\
\text { wheelchair. The LATV } \\
\text { realized his ramp } \\
\text { deployment error and } \\
\text { assisted the wheelchair } \\
\text { passenger by tilting the } \\
\text { wheelchair up and to } \\
\text { over to the right to get } \\
\text { wheelchair onto the } \\
\text { ramp. }\end{array}$} & $\begin{array}{l}\text { Side } \\
\text { Barriers }\end{array}$ & & & $X$ \\
\hline & & Slope & & & $X$ \\
\hline & & $\begin{array}{l}\text { LATV } \\
\text { Component }\end{array}$ & & & $X$ \\
\hline & & $\begin{array}{l}\text { Wheelchair- } \\
\text { seated } \\
\text { Passenger }\end{array}$ & & & $X$ \\
\hline & & Operator & & $\mathrm{X}$ & \\
\hline \multirow{7}{*}{96} & \multirow{7}{*}{$\begin{array}{l}\text { WC Type: Power WC. } \\
\text { Ramp extension: } \\
\text { Sidewalk level. } \\
\text { Wheelchair passenger } \\
\text { experienced slight } \\
\text { difficulty at the ramp } \\
\text { threshold. The first } \\
\text { attempt involved good } \\
\text { wheelchair alignment } \\
\text { with the ramp but front } \\
\text { casters were caught } \\
\text { between the ramp } \\
\text { threshold and the } \\
\text { sidewalk and grass } \\
\text { surfaces. The ramp was } \\
\text { deployed onto the grass } \\
\text { but the ramp edge was } \\
\text { 2-3 inches away from } \\
\text { the sidewalk surface. } \\
\text { The wheelchair } \\
\text { passenger backed her } \\
\text { wheelchair out of the } \\
\text { ramp and made a second } \\
\text { attempt to go up but this } \\
\text { time, with more driving }\end{array}$} & Width & $\mathrm{x}$ & & \\
\hline & & $\begin{array}{l}\text { Ramp } \\
\text { Threshold }\end{array}$ & & $\mathrm{X}$ & \\
\hline & & $\begin{array}{l}\text { Side } \\
\text { Barriers }\end{array}$ & $\mathrm{x}$ & & \\
\hline & & Slope & $\mathrm{x}$ & & \\
\hline & & $\begin{array}{l}\text { LATV } \\
\text { Component }\end{array}$ & $\mathrm{X}$ & & \\
\hline & & $\begin{array}{l}\text { Wheelchair- } \\
\text { seated } \\
\text { Passenger }\end{array}$ & & $\mathrm{X}$ & \\
\hline & & Operator & & $\mathrm{X}$ & \\
\hline
\end{tabular}




\begin{tabular}{|c|c|c|c|c|}
\hline & $\begin{array}{l}\text { power. She was able to } \\
\text { successfully ascend the } \\
\text { ramp. }\end{array}$ & & & \\
\hline \multirow{7}{*}{110} & \multirow{7}{*}{$\begin{array}{l}\text { WC Type: Power WC. } \\
\text { Ramp extension: Street } \\
\text { level. Passenger had to } \\
\text { re-align w/c } 3 \text { times } \\
\text { before successfully } \\
\text { traversing ramp into } \\
\text { LATV. On 1st attempt, } \\
\text { right rear wheel } \\
\text { contacted right side } \\
\text { barrier and passenger } \\
\text { drove back onto } \\
\text { sidewalk to realign. On } \\
\text { 2nd attempt, passenger } \\
\text { drove slower \& made } \\
\text { multiple adjustments } \\
\text { while proceeding up } \\
\text { ramp - same right rear } \\
\text { wheel appeared to strike } \\
\text { the right side barrier. } \\
\text { On the third attempt, } \\
\text { passenger drove down } \\
\text { ramp slightly (but not } \\
\text { off) to straighten all } \\
\text { wheels; realigned \& } \\
\text { successfully entered } \\
\text { LATV. }\end{array}$} & Width & $\mathrm{X}$ & \\
\hline & & $\begin{array}{l}\text { Ramp } \\
\text { Threshold }\end{array}$ & $\mathrm{x}$ & \\
\hline & & $\begin{array}{l}\text { Side } \\
\text { Barriers }\end{array}$ & $\mathrm{X}$ & \\
\hline & & Slope & $\mathrm{X}$ & \\
\hline & & $\begin{array}{l}\text { LATV } \\
\text { Component }\end{array}$ & $\mathrm{x}$ & \\
\hline & & $\begin{array}{l}\text { Wheelchair- } \\
\text { seated } \\
\text { Passenger }\end{array}$ & & $\mathrm{X}$ \\
\hline & & Operator & $\mathrm{X}$ & \\
\hline \multirow[t]{6}{*}{111} & \multirow{6}{*}{$\begin{array}{l}\text { WC Type: Scooter. } \\
\text { Ramp Extension: } \\
\text { Sidewalk. Wheelchair } \\
\text { passenger was boarding } \\
\text { from slight right of } \\
\text { ramp; driving somewhat } \\
\text { quickly. Rear right } \\
\text { wheel of scooter } \\
\text { appeared to catch on } \\
\text { right side barrier } \\
\text { (relative to the } \\
\text { passenger); passenger } \\
\text { immediately put feet out } \\
\text { on both sides onto the } \\
\text { ramp surface to steady } \\
\text { scooter and proceeded }\end{array}$} & Width & $\mathrm{X}$ & \\
\hline & & $\begin{array}{l}\text { Ramp } \\
\text { Threshold }\end{array}$ & $\mathrm{X}$ & \\
\hline & & $\begin{array}{l}\text { Side } \\
\text { Barriers }\end{array}$ & $\mathrm{X}$ & \\
\hline & & Slope & $\mathrm{X}$ & \\
\hline & & $\begin{array}{l}\text { LATV } \\
\text { Component }\end{array}$ & $\mathrm{X}$ & \\
\hline & & $\begin{array}{l}\text { Wheelchair- } \\
\text { seated } \\
\text { Passenger }\end{array}$ & & $\mathrm{X}$ \\
\hline
\end{tabular}




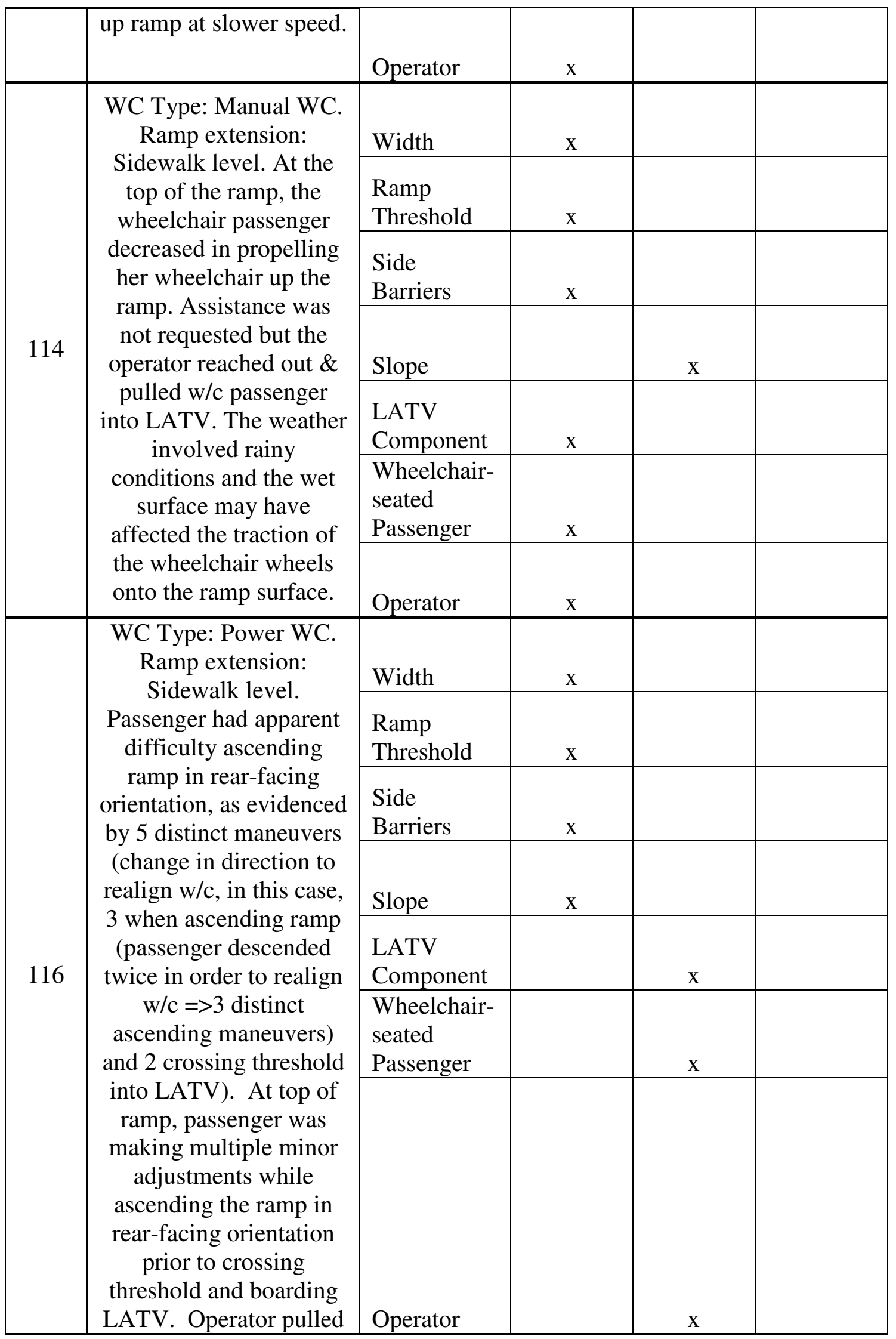




\begin{tabular}{|c|c|c|c|c|}
\hline $\begin{array}{c}\text { w/c up ramp until rear } \\
\text { wheels crossed } \\
\text { threshold. After } \\
\text { operator released w/c, } \\
\text { the passenger bumped } \\
\text { his right shoulder into } \\
\text { doorframe. He } \\
\text { realigned the w/c, made } \\
\text { it further in - but } \\
\text { bumped into the door \& } \\
\text { handrail the 2nd time. } \\
\text { On the 3rd attempt he } \\
\text { successfully entered }\end{array}$ & & & & \\
LATV. & & & \\
\hline
\end{tabular}


APPENDIX III.

ADVERSE EGRESS EVENT EVALUATION OF CURRENT LEGISLATIVE

GUIDELINES

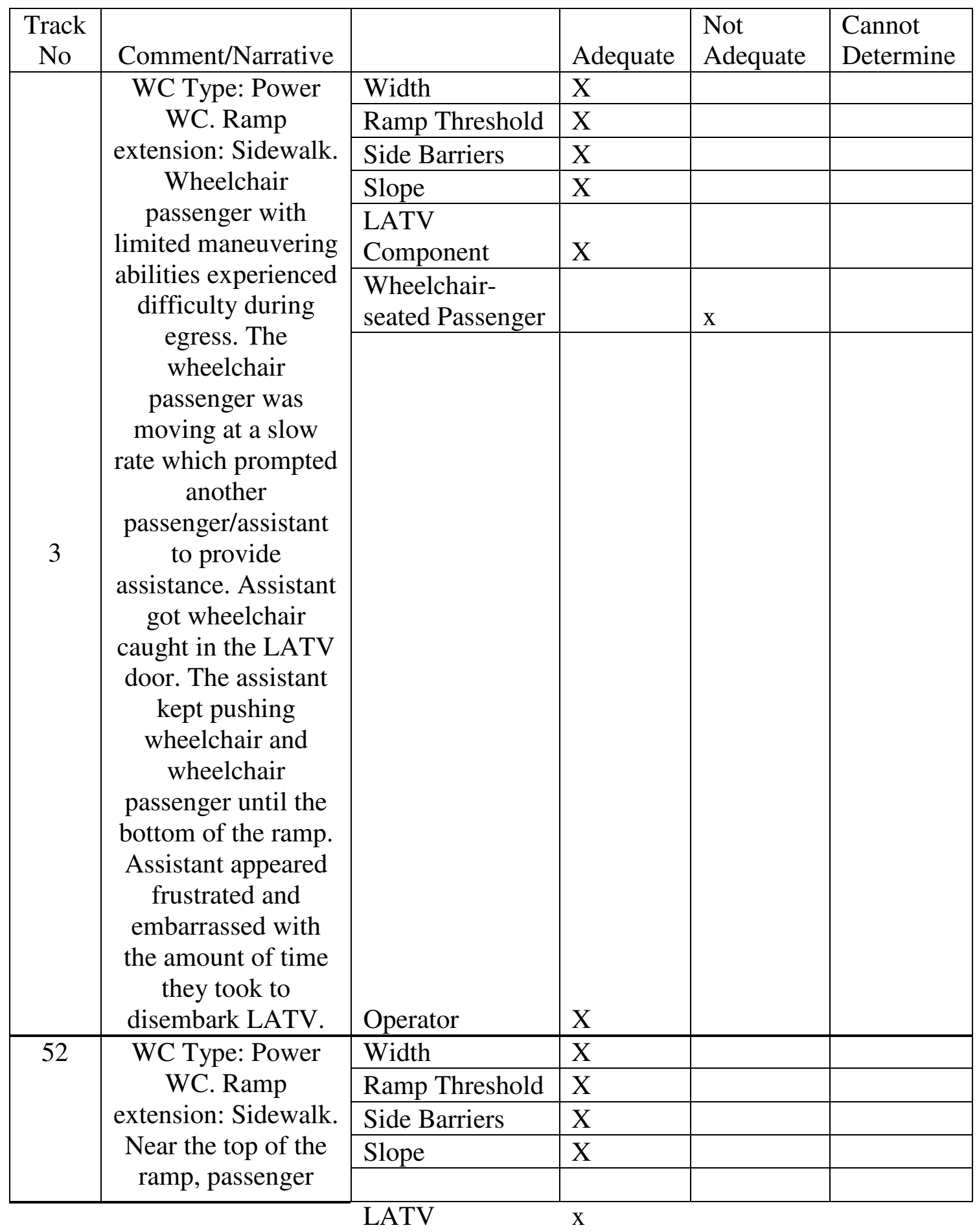




\begin{tabular}{|c|c|c|c|c|}
\hline & \multirow[b]{3}{*}{$\begin{array}{l}\text { drove wheelchair } \\
\text { caster off of the } \\
\text { right side of the } \\
\text { ramp. The operator } \\
\text { provided immediate } \\
\text { assistance. At this } \\
\text { time, the passenger } \\
\text { stood up from the } \\
\text { wheelchair and } \\
\text { allowed the LATV } \\
\text { operator assistance. } \\
\text { The operator tilted } \\
\text { the wheelchair back } \\
\text { and onto the ramp. } \\
\text { Once the passenger } \\
\text { sat back down in the } \\
\text { wheelchair, LATV } \\
\text { operator continued } \\
\text { to guide passenger } \\
\text { down the ramp. }\end{array}$} & Component & & \\
\hline & & $\begin{array}{l}\text { Wheelchair- } \\
\text { seated Passenger }\end{array}$ & & $\mathrm{x}$ \\
\hline & & Operator & $X$ & \\
\hline \multirow[b]{7}{*}{53} & \multirow{7}{*}{$\begin{array}{l}\text { WC Type: Power } \\
\text { WC. Ramp } \\
\text { extension: Sidewalk. } \\
\text { Passenger drove } \\
\text { towards the left edge } \\
\text { of the ramp. When } \\
\text { the operator saw that } \\
\text { the passenger might } \\
\text { drive off of the } \\
\text { ramp, she verbally } \\
\text { warned her and } \\
\text { advised her to back } \\
\text { up to realign the } \\
\text { WC and then } \\
\text { continue to go down } \\
\text { the ramp. The WC } \\
\text { passenger followed } \\
\text { the instructions and } \\
\text { successfully got off } \\
\text { the ramp. This event } \\
\text { occurred during } \\
\text { nighttime. }\end{array}$} & Width & $\mathrm{X}$ & \\
\hline & & Ramp Threshold & $\mathrm{X}$ & \\
\hline & & Side Barriers & $\mathrm{X}$ & \\
\hline & & Slope & $\mathrm{X}$ & \\
\hline & & $\begin{array}{l}\text { LATV } \\
\text { Component }\end{array}$ & $X$ & \\
\hline & & $\begin{array}{l}\text { Wheelchair- } \\
\text { seated Passenger }\end{array}$ & & $\mathrm{x}$ \\
\hline & & Operator & $\mathrm{X}$ & \\
\hline \multirow[t]{4}{*}{120} & \multirow{4}{*}{$\begin{array}{c}\text { WC Type: Power } \\
\text { WC. Ramp } \\
\text { extension: Sidewalk. } \\
\text { Ramp was deployed }\end{array}$} & Width & $\mathrm{X}$ & \\
\hline & & Ramp Threshold & $\mathrm{X}$ & \\
\hline & & Side Barriers & $\mathrm{X}$ & \\
\hline & & Slope & $\mathrm{X}$ & \\
\hline
\end{tabular}




\begin{tabular}{|c|c|c|c|}
\hline $\begin{array}{c}\text { onto (positive) } \\
\text { sloped dirt/grass }\end{array}$ & \begin{tabular}{|l|} 
LATV \\
Component
\end{tabular} & $X$ & \\
\hline $\begin{array}{l}\text { between the street \& } \\
\text { sidewalk. Passenger }\end{array}$ & $\begin{array}{l}\text { Wheelchair- } \\
\text { seated Passenger }\end{array}$ & & $\mathrm{x}$ \\
\hline $\begin{array}{l}\text { drove down the } \\
\text { ramp, but when the } \\
\text { forward wheels } \\
\text { reached the } \\
\text { dirt/grass, the w/c } \\
\text { got stuck w/forward } \\
\text { wheels on dirt/grass } \\
\text { and rear wheels on } \\
\text { ramp. Operator had } \\
\text { to push w/c forward } \\
\text { \& up the slope to the } \\
\text { sidewalk (it } \\
\text { appeared that after } \\
\text { the initial push that } \\
\text { the w/c was able to } \\
\text { negotiate the } \\
\text { terrain). }\end{array}$ & Operator & X & \\
\hline
\end{tabular}




\section{CURRICULUM VITAE}

\section{CONTACT INFORMATION}

Sheryll Sison, BS

1866 Rutherford Avenue, Louisville, KY 40205

Phone: 502.417.6899 Email: sheryll.sison@gmail.com

\section{EDUCATION}

Master of Engineering in Mechanical Engineering, May 2009 GPA 3.3/4.0

University of Louisville, Louisville, Kentucky

Thesis: Investigation of Wheelchair Ingress/Egress in Large Accessible Transit Vehicles and Evaluation of ADA Ramp Guidelines for Improved Ramp Safety and Usability

Bachelor of Science in Mechanical Engineering, May 2007 GPA 3.2/4.0

University of Louisville, Louisville, Kentucky

Minor in Spanish, May 2007

\section{RELEVANT EXPERIENCE}

Lexmark International, Hardware Engineer

Lexington, KY September 2008 - present

- Design and development of Fall 2009 inkjet products for waste ink management, pump mechanisms, and ink misting

- Evaluate acoustics performance in terms of customer experience and industry specifications

- Ensure robustness of inkjet products to withstand shipping and handling without degradation to appearance or function

Injury Risk Assessment and Prevention Laboratory, Graduate Research Engineer University of Louisville, Louisville, KY January 2007 - September 2008

- Investigated and assess incidents on public transit buses involving wheelchair-seated passengers as a part of the Rehabilitation Engineering Research Center

Evaluated current wheelchair ramp designs and standards for wheelchair ramps

- Developed design improvements to decrease the number and severity of injuries due to poor ramp design

- Designed and implemented wheelchair transportation monitoring database

- Developed and documented all written procedures for project

- Investigated joint kinematics associated with pediatric free standing falls using a 12month anthropometric test device

- Digitized video of pediatric free standing falls to evaluate joint kinematics across two levels of joint stiffness and five impact surfaces

Engineers Without Borders, Design and Field Engineering Student University of Louisville, August 2006 - May 2007

- Designed a portable dental unit as a member of a multidisciplinary team of engineers and dentists 
- Conducted on-site field testing and provided prototype improvements in remote area of Belize

- Obtained grant funding from University of Louisville School of Dentistry to construct dental prototype

General Electric Company, Consumer \& Industrial, Technology Co-op

Louisville, KY, 8/2004 - 1/2005 and 5/2005 - 8/2005

- Researched material options for cost efficiency and producibility of transmission gears

for new washing machine product

- Documented component wear measurement procedures for product reliability

- Performed competitive analysis for over-the-range microwave ovens

- Helped with design and execution of microwave performance test procedures

\section{LEADERSHIP EXPERIENCE}

SOCIETY OF WOMEN ENGINEERS, 2002 - present

Bluegrass Kentucky Professional Section, member, September 2008 - present

- Counselor for University of Kentucky Section, April 2008 - present

University of Louisville Section, President, Fall 2006 - Spring 2008

- Increased student membership by $100 \%$

- Represented chapter at conferences/seminars on university, regional, and national levels

- Student member, Kentuckiana SWE Professional Section

AMERICAN SOCIETY OF MECHANICAL ENGINEERS, 2002 - 2007

Engineering Expo Chair, Fall 2006 - Spring 2007

Vice President, Fall 2005 - Summer 2006

- Applied and received ASME Diversity Grant in Fall 2005 to organize ASME - SWE

Car Shop Class Series

- Planned and organized member events; scheduled and facilitated organization meetings

- Organized student group activities for University of Louisville Engineering Expo event

J.B. SPEED SCHOOL OF ENGINEERING

University of Louisville, $2006-2008$

- Member, Student Council

- Student member of Diversity Committee

\section{AWARDS AND RECOGNITION}

- Poster Competition Finalist, Top Ten in Graduate Level

Society of Women Engineers National Conference, Nashville, TN, October 2007

- Blackerby Grant, Portable Dental Unit Design Project, January 2007

University of Louisville School of Dentistry

Project Coordinator and Lead Engineer

- University of Louisville Society of Women Engineers Award, April 2006

- Modern Languages Fund Scholar Recipient, April 2006 
- Richard and Constance Lewis Scholar, April 2006

Study Abroad, Segovia, Spain

- Kentucky Society of Professional Engineers Distinguished Service Award, February 2006

- Diversity Action Grant, Car Shop Class Series

American Society of Mechanical Engineers, December 2005

Program Coordinator

- University of Louisville, Trustee Scholar

\section{PRESENTATIONS}

- Rehabilitation Engineering and Assistive Technology Society of North America, Washington, DC, June 2008

Paper Title: Wheelchair Ingress/Egress Activities on Large Accessible Transit Vehicles Platform Presentation Session

- Society of Women Engineers National Conference, Nashville, TN, October 2007

Poster Title: Assessing Kinematics of Pediatric Falls Using an Anthropomorphic Test Device

- Industrial Board of Advisors, University of Louisville Speed School of Engineering, June 2007

Blackerby Grant Foundation, University of Louisville School of Dentistry, May 2007 Title: Portable Dental Unit Design Project 